\title{
Rational bubbles and macroeconomic fluctuations: the (de-)stabilizing role of monetary policy $^{*}$
}

\author{
Lise Clain-Chamosset-Yvrard ${ }^{\dagger}$ and Thomas Seegmuller ${ }^{\ddagger}$
}

First version: March 2012

This version: April 2013

\begin{abstract}
We are interested in the occurrence of expectation-driven fluctuations of a rational bubble and the (de-)stabilizing role of monetary policy. Our explanation of fluctuations is based on credit market imperfections. For this purpose, we consider an overlapping generations exchange economy where households realize a portfolio choice between money and bubble. Money is held because of a partial cash-in-advance constraint affected by the bubble. Bubble acts as a store of value, but also as a collateral. Indeed, a higher value of the bubble implies a higher amount of collateral, which, in turn, reduces the need of cash, and thus increases consumption purchased on credit. Under these credit market features, expectation-driven fluctuations and the multiplicity of steady-states occur, in particular for arbitrarily small market distortions. Investing the stabilizing role of monetary policy, we show that when the monetary policy rule depends on expected inflation only, a more active rule stabilizes only if collateral has a large effect on consumption financed on credit. Finally, we enrich this rule by including asset prices. A policy which depends on asset prices can stabilize whatever the effect of collateral and can also rule out the multiplicity of steady states. More generally, this paper emphasizes the
\end{abstract}

\footnotetext{
*We would like to thank Edouard Challe, Jean-Michel Grandmont, Takashi Kamihigashi, Hubert Kempf, Olivier Loisel, Carine Nourry, Yiannis Vailakis, Alain Venditti and Bertrand Wigniolle for useful suggestions. We also thank participants to the Bilkent University macroeconomic seminar, to the Conference in honor of Cuong Le Van held in University Paris 1 on December 2011, to the workshop OLG Days held in Aix-Marseille University on May 2012, to the Conference PET 2012, to the Conference 11th "Journées Louis-André Gérard-Varet", to the Conference SAET 2012. Any remaining errors are our own.

${ }^{\dagger}$ Corresponding author. Aix-Marseille University (Aix-Marseille School of Economics), CNRS-GREQAM and EHESS, Centre de la Vieille Charité, 2 rue de la Charité, 13236 Marseille CEDEX 02, France. E-mail: lise.clain-chamosset-yvrard@univ-amu.fr.

¥Aix-Marseille University (Aix-Marseille School of Economics), CNRS-GREQAM and EHESS, Centre de la Vieille Charité, 2 rue de la Charité, 13236 Marseille CEDEX 02, France. E-mail: thomas.seegmuller@univ-amu.fr.
} 
key role of consumers' credit market imperfections to explain bubble fluctuations and exhibits the stabilizing power of monetary rules including asset prices.

JEL classification: D91, E32, E52.

Keywords: Rational bubble; Cash-in-advance constraint; Collateral; Endogenous fluctuations; Monetary policy.

\section{Introduction}

Over the last decades, financial markets have frequently gone through periods of excessive asset price volatility. Some empirical studies, Shiller (1981, 1989, 2000), LeRoy and Porter (1981), and more recently Campbell (2003), highlight this excess volatility and reveal that asset prices tend to fluctuate more than their fundamentals. These contributions reflect the idea that the excess volatility could come from fluctuations of a bubble.

In the collective consciousness, and many political debates, the fluctuations of a bubble are often associated to the irrational behavior of agents. In 1996, Alan Greenspan uses the expression "irrational exuberance" to describe the movements of speculative bubbles in financial markets. ${ }^{1}$ In this paper, we provide an alternative justification of such fluctuations, which lies in the volatility of rational expectations, i.e. in the existence of persistent expectation-driven fluctuations of a rational bubble.

In addition, asset prices are in the heart of another debate, namely whether central banks should take or not into account asset price movements in monetary policy. As for academic research, the debate is not resolved: among others, Bernanke and Gertler (2001), Gilchrist and Leahy (2002), Carlstrom and Fuerst (2007) and Gali (2011) provide a negative answer about including asset prices in monetary rules, whereas Nutahara (2010) and Singh and Stone (2011) develop models in favor of it. Interestingly, these two last papers take into account credit market frictions. Moreover, several Governors of central bank or practitioners of monetary policy recently encourage more research on these topics. In his recent speech, Bernanke (2011) argues that: "In my view, the issue is not whether central bankers should ignore possible financial imbalances -they should notbut, rather, what "the right tool for the job" is to respond to such imbalances." In our framework, we also contribute to this debate. A monetary policy, which responds to movements in asset prices, stabilizes economic fluctuations with the existence of a rational bubble, whereas this is not always the case when the rule depends on inflation forecasts only.

We build a simple general equilibrium model in which rational bubbles could experience persistent fluctuations, and also allowing us to study the (de-)stabilizing role of monetary policy. Our explanation is mainly based on credit market imperfections, the role of the bubble as a collateral, and a portfolio choice between two assets, money and a bubble. In contrast to recent con-

\footnotetext{
${ }^{1}$ This expression is also taken up by Robert Shiller (2000) as the title of his book.
} 
tributions studying the link between rational bubbles and credit market imperfections faced by entrepreneurs (Farhi and Tirole (2010), Kocherlakota (2009)), but more in line with Kocherlakota (1992) or Hellwig and Lorenzoni (2009), we focus on consumers' credit constraints. ${ }^{2}$ We introduce such constraints in a monetary overlapping generations (OLG) model. Referring to Tirole's seminal papers $(1982,1985)$, the OLG model provides a simple and useful framework to deal with the existence of rational bubbles. ${ }^{3}$

The issue of fluctuations of a rational bubble within an OLG model has been addressed only in few contributions (Grandmont (1985), Weil (1987), Michel and Wigniolle (2003, 2005), Bosi and Seegmuller (2010) and Wigniolle (2012)). Our aim is to provide an additional explanation of expectation-driven fluctuations of a bubble based on credit market imperfections, and to study the (de-)stabilizing role of monetary rules responding to inflation forecasts and asset prices. ${ }^{4}$

We consider an exchange economy in which households realize a portfolio choice between an asset without fundamental value (the bubble) and money needed for transactions. More precisely, money is held because of a binding cash-in-advance constraint on the second-period consumption purchases. ${ }^{5}$ A share of second-period consumption is paid in cash with monetary savings, while the remaining share is purchased on credit by borrowing against non-monetary savings. In our model, the cash-in-advance constraint reflects credit market imperfections.

One important feature is that the share of consumption purchased on credit depends positively on the value of the bubble. The bubble serves as a collateral, i.e. a credit guarantee for households. If households hold more savings in the form of bubble, the amount of collateral increases, which allows households to increase their opportunity to obtain credits, and thus their share of consumption purchased on credit. This assumption also means that distortions in credit market are decreasing in collateral. Since we focus on a binding cash-in-advance constraint, the portfolio choice is endogenously determined and variable over time depending on expectations about future asset prices.

Our main results lean on credit market features. Whatever the level of credit market imperfections, expectation-driven fluctuations and two-period cycles occur under large income effects, i.e. when savings are an increasing function of expected inflation. This result is closely related to Grandmont $(1985,1986)$. More

\footnotetext{
${ }^{2}$ Some empirical studies highlight finance constraints at the household level. See for instance Campbell and Mankiw (1989).

${ }^{3}$ However, the existence of rational bubbles could also be provided in infinitely-lived household models. For instance, Kocherlakota (1992) develops a model with heterogeneous agents and borrowing constraints, and Kamihigashi (2008) an economy with wealth in the utility function.

${ }^{4}$ Hence, even if we do not consider capital accumulation, we generalize the analysis provided in Bosi and Seegmuller (2010) in two directions. First, we provide a more deeply analysis of dynamics, and second, we consider monetary policies not only characterized by a constant growth rate.

${ }^{5}$ See Hahn and Solow (1995). For further details about cash-in-advance constraints in a OLG model, the reader can refer to Crettez et al. (1999). In addition, in contrast to Michel and Wigniolle $(2003,2005)$, we focus on equilibria for which the cash-in-advance constraint is always binding. As a consequence, bubbles on real money balances cannot exist.
} 
interestingly, a rational bubble also experiences fluctuations due to the volatility of expectations under slightly restrictive conditions, i.e. for arbitrarily small credit market imperfections and for relatively small income effects. This result answers a recurrent criticism about endogenous fluctuations in monetary OLG models. The intuition is the following. As collateral matters, a change in the portfolio structure takes place. A rise in expected inflation generates a portfolio effect: households reallocate savings from monetary to non-monetary savings, i.e. increase the share of the bubble in total savings. The amount of collateral increases. As a consequence, households consume less by cash in the second period of life. The return on money decreases. An effective rise in inflation takes place, and expectations are self-fulfilling. In connection with this result, we show that the multiplicity of steady states occurs under the same conditions: convergence or not to a steady state may depend on agents' expectations.

We pursue by analyzing the stabilizing role of monetary policy on the fluctuations of the rational bubble. The question of whether monetary policy can stabilize endogenous fluctuations has been essentially studied in models without portfolio choice and without collateral (Grandmont (1985, 1986), Sorger (2005)). While Grandmont $(1985,1986)$ suggests monetary policies coordinating expectations, Sorger (2005) studies monetary rules based on inflation forecast targeting, ${ }^{6}$ which alter conditions for local indeterminacy. He shows that an active rule, i.e. a monetary rule which strongly reacts to expected inflation, ${ }^{7}$ destabilizes by increasing the range of parameter values for which local indeterminacy occurs. We get the same conclusions for small collateral effects. However, we show that the presence of collateral can reverse this established result: an active inflation forecast targeting rule locally stabilizes fluctuations occurring for large income effects as soon as the effect of collateral on the share of consumption purchased on credit is large enough. However, inflation forecast targeting has no impact on fluctuations, which occur for small income effects, and does not modify conditions under which the multiplicity of steady states may occur. Such a rule locally stabilizes, but not globally.

We further examine whether a monetary rule, responding to movements in asset prices, is appropriate to stabilize an economy, which experiences persistent fluctuations of a bubble. We extend the rule of inflation targeting proposed by Sorger (2005) by including asset prices. A monetary rule with asset prices could locally and globally stabilize fluctuations unlike a monetary rule which responds only to inflation. More precisely, when collateral has a small effect on the share of consumption purchased on credit, a passive monetary rule is stabilizing, and when collateral sufficiently matters, an active one is stabilizing. Following the debate initiated by Bernanke and Gertler $(1999,2001)$ and recently advanced by several Governors of central bank or practitioners of monetary policy (Yellen (2009), Bernanke (2010, 2011)), a monetary policy including asset prices is powerful to rule out expectation-driven fluctuations.

The rest of the paper is organized as follows. The Section 2 is devoted to the

\footnotetext{
${ }^{6}$ Note that in a recent speech, Bernanke (2010) explains, however, that the US monetary policy follows more closely such a rule than one based on observed inflation.

${ }^{7}$ Following Sorger (2005), we adopt the terminology initiated by Benhabib et al. (2001).
} 
presentation of the model. In Section 3, the intertemporal equilibrium is defined. Steady states with a bubble are studied in Section 4. In Section 5, we show the existence of bubble fluctuations. Section 6 discusses the (de-)stabilizing role of monetary policies. A last section provides concluding remarks, whereas some technical details are relegated to an Appendix.

\section{The model}

We focus on an OLG exchange economy with identical two period-lived households, discrete time $(t=0,1, \ldots,+\infty)$ and three goods: a final good, money and an asset paper.

\subsection{Households}

There is no population growth and, at each date $t$, a generation of unit size is born. Each generation lives two periods.

In her first period of life, a household is endowed with $e \geq 0$ units of consumption good and receives a monetary transfer $T_{t}$ from the monetary authority that she allocates between the purchase of the consumption good $c_{t}$ at price $p_{t}$ and savings in the form of nominal balances $M_{t+1}$ and an asset paper without fundamental value, which corresponds to non-monetary savings. Let $B_{t}$ be the nominal value of non-monetary savings and $1+i_{t+1}$ the return factor between $t$ and $t+1$. In her second period of life, since the household has neither endowments nor a monetary transfer, she uses her remunerated savings $M_{t+1}+\left(1+i_{t+1}\right) B_{t}$ to consume $d_{t+1}$ at price $p_{t+1}$.

The preferences of a household are represented by an additively separable life-cycle utility function:

$$
u\left(c_{t}\right)+\beta v\left(d_{t+1}\right)
$$

where $\beta>0$, and $c_{t}$ and $d_{t+1}$ respectively denote the consumption of final good in the first and second period of life.

Assumption $1 u(c)$ and $v(d)$ are continuous functions defined on $[0,+\infty)$, $C^{2}$ on $(0,+\infty)$, strictly increasing $\left(u^{\prime}>0, v^{\prime}>0\right)$ and concave $\left(u^{\prime \prime}<0, v^{\prime \prime}<0\right)$. Moreover, $\lim _{c \rightarrow 0} u^{\prime}(c)=+\infty$ and $\lim _{d \rightarrow 0} v^{\prime}(d)=+\infty$. We define $\varepsilon_{u}(c) \equiv$ $-c \frac{u^{\prime \prime}(c)}{u^{\prime}(c)}$ and $\varepsilon_{v}(d) \equiv-d \frac{v^{\prime \prime}(d)}{v^{\prime}(d)}$ as the degrees of concavity of $u(c)$ and $v(d)$ respectively.

Under perfect foresight, the representative household of a generation born at time $t$ derives consumption plan and savings (money and asset paper) by maximizing the utility function (1) under the first and second-period budget constraints:

$$
\begin{aligned}
p_{t} c_{t}+M_{t+1}+B_{t} & \leq p_{t} e+T_{t} \\
p_{t+1} d_{t+1} & \leq M_{t+1}+\left(1+i_{t+1}\right) B_{t}
\end{aligned}
$$


Furthermore, in the second period of life, each household faces a cash-in-advance constraint. We use the constraint introduced by Hahn and Solow (1995), i.e. $\gamma p_{t+1} d_{t+1} \leq M_{t+1}$, but affected by the presence of collateral.

$$
\gamma\left(b_{t}\right) p_{t+1} d_{t+1} \leq M_{t+1}
$$

where $b_{t} \equiv B_{t} / p_{t}$ is the real amount of non-monetary savings.

A binding cash-in-advance constraint means that households finance a share $\gamma\left(b_{t}\right) \in(0,1)$ of second-period consumption by cash with monetary savings. The remaining share $1-\gamma\left(b_{t}\right)$ is financed by borrowing against the resale of non-monetary savings, i.e. the asset paper sold in the financial markets at the end of the second period valued at $\left(1+i_{t+1}\right) B_{t}$. In other words, $1-\gamma\left(b_{t}\right)$ represents the share of consumption purchased on credit. For further reference, we refer to $1-\gamma\left(b_{t}\right)$ as the credit share. ${ }^{8}$

In addition, we assume that the credit share depends positively on the amount of non-monetary savings for two reasons: the velocity of money and the credit market frictions. First, we give an answer to a recurrent criticism addressed to the cash-in-advance literature: money velocity $1 / \gamma\left(b_{t}\right)$ is endogenous and no longer constant. Second, through this assumption, we capture some unmodeled financial frictions in borrower-lender relationship as asymmetric information or financial regulation policy. This is a simple manner to introduce credit market imperfections including a collateral effect in our framework. Real non-monetary savings (asset paper) act as a collateral: if households hold more savings in the form of asset paper, ${ }^{9}$ the amount of collateral increases, which allows households to increase their opportunity to obtain credits, and thus to reduce their need of cash in their second period of life. ${ }^{10}$

Assumption $2 \gamma(b) \in(0,1)$ is a continuous function defined on $[0,+\infty), C^{2}$ on $(0,+\infty)$, decreasing $\left(\gamma^{\prime}(b) \leq 0\right)$ and such that $\gamma(0)<1-\epsilon$, where $\epsilon$ is sufficiently close to zero. In addition, we define:

$$
\begin{aligned}
\eta_{1}(b) & \equiv \frac{[1-\gamma(b)]^{\prime} b}{1-\gamma(b)} \geq 0, \eta_{2}(b) \equiv-\frac{[1-\gamma(b)]^{\prime \prime} b}{[1-\gamma(b)]^{\prime}} \\
\eta_{\eta}(b) & \equiv \frac{\eta_{1}^{\prime}(b) b}{\eta_{1}(b)}=1-\eta_{1}(b)-\eta_{2}(b)
\end{aligned}
$$

As an example, the following function satisfies these properties:

$$
\gamma(b)=\frac{A}{s} \exp (-s b)
$$

\footnotetext{
${ }^{8}$ A similar idea can be seen in Lucas and Stokey (1987), where consumption purchased with money would correspond to "cash goods" and consumption purchased on credit to "credit goods".

${ }^{9}$ Take in mind that the present value of a bubble asset embodies future values.

${ }^{10}$ Since $b_{t}$ depicts the real amount of non-monetary savings of an household (e.g. the household estate), $b_{t}$ instead of $b_{t+1}$ represents a collateral.
} 
with $0<A<s(1-\epsilon)$. From this function given by Eq. (7), we can derive $\eta_{1}(b)$ and $\eta_{2}(b)$ such that:

$$
\eta_{1}(b)=\frac{A \exp (-s b)}{1-\frac{A}{s} \exp (-s b)} b \geq 0 \text { and } \eta_{2}(b)=s b>0
$$

Notice that when collateral plays no role $\left(\eta_{1}(b)=0\right)$, and $\gamma$ tends to 0 , money is no longer needed and the credit market distortions disappear. When collateral matters $\left(\eta_{1}(b)>0\right)$, the household is aware of the credit share function, $1-\gamma\left(b_{t}\right)$, so that she takes into account its argument $b_{t}$ in her decisions.

Using $\pi_{t+1} \equiv p_{t+1} / p_{t}$ and introducing the real variables $m_{t} \equiv M_{t} / p_{t}$ and $\tau_{t} \equiv T_{t} / p_{t}$, the constraints (2)-(4) can be rewritten:

$$
\begin{aligned}
c_{t}+\pi_{t+1} m_{t+1}+b_{t} & \leq e+\tau_{t} \\
d_{t+1} & \leq m_{t+1}+\frac{1+i_{t+1}}{\pi_{t+1}} b_{t} \\
\gamma\left(b_{t}\right) d_{t+1} & \leq m_{t+1}
\end{aligned}
$$

The representative household maximizes (1) under the budget and cash-inadvance constraints (8)-(10) to determine optimal consumption plan $\left(c_{t}, d_{t+1}\right)$ and optimal real savings $\left(m_{t+1}, b_{t}\right)$. All constraints are binding if money is a dominated asset $\left(\left(1+i_{t+1}\right) / \pi_{t+1}>1 / \pi_{t+1}\right)$, or equivalently the opportunity cost of holding money, the nominal interest rate $i_{t+1}$, is strictly positive $\left(i_{t+1}>\right.$ $0)$. Only a bubble on the asset paper could appear.

In the remaining of the paper, we only consider the case of a binding cash-inadvance constraint so that the portfolio choice is determined. The asset paper holdings, whose the level depends on expectations about its future value, determine the money demand used for future consumption. Nonetheless, because of the endogeneity of the credit share, the portfolio choice is no longer constant. The trade-off between assets becomes endogenous and depends on the amount of collateral held by the household implying the existence of a "portfolio effect". This portfolio effect could be seen as a substitution effect within the portfolio following a change in the relative price between the two assets. Thereafter, we will see that this portfolio effect is a key mechanism through which expectationdriven fluctuations emerge.

Assumption 3 For all $t \geq 0$, we assume $i_{t}>0$ and

$$
\eta_{1}\left(b_{t}\right)<\frac{\gamma\left(b_{t}\right)}{1-\gamma\left(b_{t}\right)} \frac{b_{t}}{\pi_{t+1} m_{t+1}}
$$

Lemma 1 Under Assumption 3, constraints (8)-(10) are binding.

Proof. See Appendix.

The inequality (11) puts an upper bound to the credit-share elasticity $\eta_{1}(b)$. It is specific to our model because of the presence of collateral. Since the righthand side is strictly positive, the inequality (11) is satisfied when the credit 
share, $1-\gamma$, is constant $\left(\eta_{1}=0\right)$. Thereafter, we focus on the case where $\eta_{1}$ is not too large. In other words, we consider small distortions in the credit market.

Under Assumption 3, the optimal households' behavior is summarized by the following equation:

$$
\begin{aligned}
\frac{u^{\prime}\left(c_{t}\right)}{\beta v^{\prime}\left(d_{t+1}\right)} & =\frac{1}{\pi_{t+1}} \frac{\left(1+i_{t+1}\right) / \pi_{t+1}+\gamma^{\prime}\left(b_{t}\right) d_{t+1}}{\left[1-\gamma\left(b_{t}\right)\right]\left[1 / \pi_{t+1}+\gamma^{\prime}\left(b_{t}\right) d_{t+1}\right]+\gamma\left(b_{t}\right)\left[\left(1+i_{t+1}\right) / \pi_{t+1}+\gamma^{\prime}\left(b_{t}\right) d_{t+1}\right]} \\
& >\frac{1}{\pi_{t+1}}
\end{aligned}
$$

where the last inequality holds because money is a dominated asset $\left(1 / \pi_{t+1}<\right.$ $\left.\left(1+i_{t+1}\right) / \pi_{t+1}\right)$. Furthermore, we deduce the following lemma ${ }^{11}$ :

Lemma 2 Let

$$
\tilde{\varepsilon}_{u} \equiv c \frac{(1-\gamma)^{2} / b}{\left[1-\gamma+(1+i)\left(\gamma-\eta_{1}\right)\right]^{2}} i \eta_{1}\left(2-\frac{\eta_{2}}{1-\eta_{1}}\right)
$$

The second-order conditions are satisfied if $\varepsilon_{u}>\tilde{\varepsilon}_{u}$.

Proof. See Appendix.

We further note that under a constant credit share $(1-\gamma(b)=1-\gamma)$, Eq. (12) rewrites:

$$
\frac{u^{\prime}\left(c_{t}\right)}{\beta v^{\prime}\left(d_{t+1}\right)}=\frac{1+i_{t+1}}{\pi_{t+1}} \frac{1}{1+i_{t+1} \gamma}
$$

When $\gamma$ tends to 0 , the right-hand side would reduce to $\left(1+i_{t+1}\right) / \pi_{t+1}$, which is similar to the trade-off found in the monetary model by Samuelson (1958). There are no market distortions. When $\gamma>0$, money demand implies an opportunity cost which lowers the real return on portfolio. More precisely, the household has to pay by cash a share $\gamma$ to consume an extra-unit when she is old. The interest rate $i_{t+1}$ entails an opportunity cost $\gamma i_{t+1}$ which reduces the purchasing power of savings in the form of asset paper. Furthermore, when the credit share depends on collateral, the marginal effect of non-monetary savings on the credit share $\left(-\gamma^{\prime}(b)>0\right)$ becomes an additional distortion.

\subsection{Monetary rule}

Let us introduce the money growth factor $\mu_{t}=M_{t+1} / M_{t}$. It can be rewritten:

$$
\mu_{t}=\pi_{t+1} \frac{m_{t+1}}{m_{t}}
$$

As in Sorger (2005), the money growth factor corresponds to the monetary instrument. ${ }^{12}$ However, focusing on bubble fluctuations, we extend the rule

\footnotetext{
${ }^{11}$ For simplicity, the arguments of the functions and the time subscripts are omitted.

${ }^{12}$ In recent work, Gaballo (2012) introduces a monetary rule, whose the monetary instrument is the money supply, to study the social value of information about the future in a OLG model of inflation.
} 
proposed by Sorger (2005), by taking deviations of observed asset prices from the target into account. Although the instrument of the rule is the money growth factor, our formulation corresponds to the one suggested by Bernanke and Gertler (1999, 2001), Carlstrom and Fuerst (2007) and Singh and Stone (2010).

The monetary policy is implemented trough an instrument rule of the following form:

$$
\mu_{t}=\mu^{*}\left(\frac{\pi_{t+1}}{\mu^{*}}\right)^{-\alpha}\left(\frac{b_{t}}{b^{*}}\right)^{-\rho},
$$

with $\alpha \in(-1,+\infty)$ and $\rho \in(-1,+\infty)$.

We clarify that $\mu^{*}$ and $b^{*}$ are respectively the stationary values of the money growth factor and the asset price level of an existing stationary equilibrium chosen as the targets by the monetary authority.

When $\alpha=0$ and $\rho=0$, the nominal money supply grows at the constant growth factor $\mu_{t}=\mu^{*}$. This policy corresponds to a regime of strict money growth targeting in which the nominal money growth rate is fixed at its stationary value $\mu^{*}$.

When $\alpha \neq 0$ and $\rho=0$, Eq. (15) depicts a policy rule for inflation forecast targeting (Sorger (2005)). When the monetary authority sets the money growth factor $\mu_{t}$, the inflation $\pi_{t+1}$ has not been observed yet and can be seen as an inflation forecast. For $\alpha>0$, the nominal money growth is a decreasing function of expected inflation. The nominal money growth is contracted if expected inflation is above its stationary value $\mu^{*}$ and expanded if expected inflation is below. For $\alpha \in(-1,0)$, the nominal money growth is an increasing function of expected inflation but less than proportional. As Benhabib et al. (2001) and Sorger (2005), we call a rule with $\alpha>0$ an active one and a rule with $\alpha \in(-1,0)$ a passive one.

When $\alpha \neq 0$ and $\rho \neq 0$, Eq. (15) depicts a monetary rule which takes into account the level of asset prices. This rule includes a response to the level of current asset prices $b_{t}$ with respect to its steady state level $b^{*}$.

This rule is in accordance with Bernanke and Gertler $(1999,2001)$. In addition, several Governors of central bank or practitioners of monetary policy encourage more research on monetary policies which would react to credit booms (Yellen (2009)). By considering $b_{t}$ as savings in the form of credit and thus as an index of the credit level, Eq. (15) could also be interpreted as a fomalisation of such a monetary policy.

For $\rho>0$, the nominal money growth is a decreasing function of current asset prices. In other words, the nominal money supply is contracted if the level of asset prices is above $b^{*}$ and expanded if the level is below. For $\rho \in(-1,0)$, the nominal money growth rate is an increasing function of current asset prices but less than proportional. In the following, we call a rule with $\rho>0$ an active one and a rule with $\rho \in(-1,0)$ a passive one.

Money is distributed by the monetary authority to young households through a lump-sum transfer $\tau_{t}=\left(M_{t+1}-M_{t}\right) / p_{t}$, or equivalently,

$$
\tau_{t}=\pi_{t+1} m_{t+1}-m_{t}
$$


Assuming that the monetary transfer is distributed in the first period of life and not in the second period, we closely follow Michel and Wigniolle (2005). This assumption seems to be appropriate to study the role of savings and the portfolio choice on dynamics. Actually, the monetary transfer distributed in the second period of life negatively affects the amount of individual savings.

\subsection{Asset paper}

Following Tirole (1985), Weil (1987) and more recently Bosi and Segmuller (2010), we assume that there is an asset paper, without fundamental value, which may be use to save. It is supplied in a constant amount, normalized to one. Thus, $B_{t}$ denotes its monetary price, and $i_{t+1}$ the growth rate of this price:

$$
B_{t+1}=\left(1+i_{t+1}\right) B_{t}
$$

The asset is called a bubble, when its price is non-negative, i.e. $B_{t}>0$. Using real variables, Eq. (17) can be rewritten:

$$
b_{t+1}=\frac{1+i_{t+1}}{\pi_{t+1}} b_{t}
$$

\section{Intertemporal equilibrium}

Substituting Eq. (16) in the first-period budget constraint (8), we determine:

$$
c_{t}+m_{t}+b_{t}=e
$$

Using Eqs. (9), (10), (18) and (19), we obtain:

$$
\begin{gathered}
m_{t+1}=b_{t+1} \frac{\gamma\left(b_{t}\right)}{1-\gamma\left(b_{t}\right)} \\
c_{t}=e-\frac{b_{t}}{1-\gamma\left(b_{t-1}\right)} \\
d_{t+1}=\frac{b_{t+1}}{1-\gamma\left(b_{t}\right)}
\end{gathered}
$$

As $c_{t}>0$, we deduce an upper bound on $b_{t}$ from Eq. (21):

$$
0 \leq b_{t}<\left[1-\gamma\left(b_{t-1}\right)\right] e \equiv \bar{b}\left(b_{t-1}\right)
$$

Using Eqs. (14), (18) and (20), we deduce the inflation factor and the rental rate on the asset paper:

$$
\begin{gathered}
\pi_{t+1}=\mu_{t} \frac{\gamma\left(b_{t-1}\right)}{\gamma\left(b_{t}\right)} \frac{1-\gamma\left(b_{t}\right)}{1-\gamma\left(b_{t-1}\right)} \frac{b_{t}}{b_{t+1}} \\
1+i_{t+1}=\mu_{t} \frac{\gamma\left(b_{t-1}\right)}{\gamma\left(b_{t}\right)} \frac{1-\gamma\left(b_{t}\right)}{1-\gamma\left(b_{t-1}\right)}
\end{gathered}
$$


Substituting Eqs.(19)-(25) into Eq. (12), we obtain the consumers' intertemporal trade-off :

$$
\frac{u^{\prime}\left(e-\frac{b_{t}}{1-\gamma\left(b_{t-1}\right)}\right)}{\beta v^{\prime}\left(\frac{b_{t+1}}{1-\gamma\left(b_{t}\right)}\right)}=\frac{\frac{b_{t+1}}{b_{t}}\left[1-\eta_{1}\left(b_{t}\right)\right]}{1-\gamma\left(b_{t}\right)+\left[\gamma\left(b_{t}\right)-\eta_{1}\left(b_{t}\right)\right] \mu_{t} \frac{\gamma\left(b_{t-1}\right)}{\gamma\left(b_{t}\right)} \frac{1-\gamma\left(b_{t}\right)}{1-\gamma\left(b_{t-1}\right)}}
$$

Note that $b_{0}$ is not predetermined in period 0 . However, the second-order recurrence equation (26) has a predetermined variable at period $t, b_{t-1}$. At this stage, it is relevant to clarify that from Assumption 1, the inequality (23) is satisfied.

From Eqs. (14), (15), and (20), we obtain:

$$
\frac{\pi_{t+1}}{\mu^{*}}=\left[\frac{\gamma\left(b_{t-1}\right)}{1-\gamma\left(b_{t-1}\right)} \frac{1-\gamma\left(b_{t}\right)}{\gamma\left(b_{t}\right)} \frac{b_{t}}{b_{t+1}}\right]^{\frac{1}{1+\alpha}}\left(\frac{b_{t}}{b^{*}}\right)^{\frac{-\rho}{1+\alpha}}
$$

Substituting Eq. (27) into Eq. (15), we get the following expression of the money growth factor:

$$
\mu_{t}=\mu^{*}\left[\frac{\gamma\left(b_{t-1}\right)}{1-\gamma\left(b_{t-1}\right)} \frac{1-\gamma\left(b_{t}\right)}{\gamma\left(b_{t}\right)} \frac{b_{t}}{b_{t+1}}\right]^{\frac{-\alpha}{1+\alpha}}\left(\frac{b_{t}}{b^{*}}\right)^{\frac{-\rho}{1+\alpha}}
$$

Definition 1 Under Assumptions 1-3, an intertemporal equilibrium with perfect foresight is a sequence $\left(b_{t}\right)$, with $0 \leq b_{t}<\bar{b}\left(b_{t-1}\right)$ and $t=0,1, \ldots,+\infty$, such that Eq. (26) is satisfied, where $\mu_{t}$ is given by Eq. (28).

For further references, note that substituting Eqs. (18) and (20) into Eq. (11) allows us to rewrite Assumption 3:

$$
1<1+i_{t+1}<1 / \eta_{1}\left(b_{t}\right)
$$

for $t=0,1, \ldots,+\infty$, which ensures that the cash-in-advance constraint is binding.

In the following, we will use this definition of the equilibrium to show the existence of expectation-driven fluctuations of the rational bubble and study the (de-)stabilizing role of monetary policy. For this purpose, we first analyze the steady state. We will see that some new interesting results, related to the multiplicity of solutions and based on credit market features, will be obtained.

\section{Steady state analysis}

A bubbly steady state is a solution solving:

$$
\frac{u^{\prime}\left(e-\frac{b}{1-\gamma(b)}\right)}{\beta v^{\prime}\left(\frac{b}{1-\gamma(b)}\right)}=\frac{1-\eta_{1}(b)}{1-\gamma(b)+\left[\gamma(b)-\eta_{1}(b)\right] \mu(b)},
$$


where $\mu(b) \equiv \mu^{*}\left(b / b^{*}\right)^{-\rho /(1+\alpha)}$ is obtained from Eq. (28).

In the following, we first study the existence of the bubbly steady state. ${ }^{13}$ Second, we establish the existence of a normalized steady state. The issue of uniqueness versus multiplicity of stationary solutions is finally addressed.

\subsection{Existence and uniqueness}

The following assumption helps us to prove the existence of a steady state with a positive bubble:

Assumption 4 If $\rho>0$,

$$
\begin{aligned}
\varepsilon_{v}(0)< & \frac{\eta_{1}(0)}{\left[1-\eta_{1}(0)\right]} \frac{[1-\gamma(0)][\mu(0)-1]}{\left\{1-\gamma(0)+\mu(0)\left[\gamma(0)-\eta_{1}(0)\right]\right\}} \\
& \left(2-\frac{\eta_{2}(0)}{1-\eta_{1}(0)}\right)+\frac{\rho}{1+\alpha} \frac{\mu(0)\left[\gamma(0)-\eta_{1}(0)\right] /\left[1-\eta_{1}(0)\right]}{1-\gamma(0)+\mu(0)\left[\gamma(0)-\eta_{1}(0)\right]}
\end{aligned}
$$

The next proposition proves the existence of a bubbly steady state and provides a result on uniqueness.

Proposition 1 Let $\bar{b}$ be defined by $e=\bar{b} /[1-\gamma(\bar{b})]$. Under Assumptions 14 , there exists a steady state characterized by a positive bubble, $b^{*} \in(0, \bar{b})$. The uniqueness of the steady state is ensured if the following condition holds $\forall$ $b \in(0, \bar{b}):$

$$
\begin{gathered}
\varepsilon_{v}(d)>\frac{b}{c[1-\gamma(b)]}\left[\varepsilon_{u}^{s}(b)-\varepsilon_{u}(c)\right] \\
\text { with } \quad \varepsilon_{u}^{s}(b) \equiv \frac{c[1-\gamma(b)]}{b}\left\{\frac{\eta_{1}(b)}{1-\eta_{1}(b)} \frac{[1-\gamma(b)][\mu(b)-1]}{1-\gamma(b)+\mu(b)\left[\gamma(b)-\eta_{1}(b)\right]}\right. \\
\left.\left(2-\frac{\eta_{2}(b)}{1-\eta_{1}(b)}\right)+\frac{\rho}{1+\alpha} \frac{\mu(b)\left[\gamma(b)-\eta_{1}(b)\right]}{1-\gamma(b)+\mu(b)\left[\gamma(b)-\eta_{1}(b)\right]} \frac{1}{1-\eta_{1}(b)}\right\} \\
c=e-\frac{b}{1-\gamma(b)} \quad \text { and } \quad d=\frac{b}{1-\gamma(b)}
\end{gathered}
$$

Proof. See Appendix.

Under a constant credit share, $1-\gamma\left(\eta_{1}=0\right)$, and a passive rule on asset prices $(\rho \leq 0)$, the condition (31) is always satisfied. This is also the case when the degrees of concavity of utility function are large enough. However, the multiplicity of steady states may occur when the condition (31) is not satisfied for all $b \in(0, \bar{b})$. We clarify this in the next section.

We remind that the monetary authority specifies targets for inflation and asset prices, choosing the stationary values of an existing steady state. From Proposition 1 , a steady state with bubble $b^{*}$ always exists. We assume that the monetary authority selects this equilibrium $b^{*}$ as a target.

\footnotetext{
${ }^{13}$ Since we are interested in persistent bubble fluctuations, we do not focus on the existence of steady states without bubble.
} 


\subsection{Normalized steady state and multiplicity}

In order to facilitate the analysis of the multiplicity of steady states and of local dynamics (Sections 5 and 6), we establish the existence of a normalized steady state $b^{*}=1$ (NSS). We follow the procedure introduced by Cazzavillan et al. (1998) and use the scaling parameter $\beta$ to give conditions for the existence of such a steady state.

Proposition 2 Under Assumptions 1-4, there exists a unique value $\beta^{*}>0$ given by

$$
\beta^{*}=\frac{u^{\prime}\left(e-\frac{1}{1-\gamma(1)}\right)}{v^{\prime}\left(\frac{1}{1-\gamma(1)}\right) \frac{1-\eta_{1}(1)}{1-\gamma(1)+\mu(1)\left[\gamma(1)-\eta_{1}(1)\right]}}
$$

such that $b^{*}=1$ is a steady state of the dynamic equation (26).

Thereafter, we assume $\beta=\beta^{*}$ so that $b^{*}=1$. At the normalized steady state, $\mu(1)=\mu^{*}=\pi$ (see Eq. (14)) and $\pi=1+i$ (see Eq. (18)). From the inequality (29), Assumption 3 is satisfied if and only if:

$$
1<\mu^{*}<1 / \eta_{1}(1)
$$

Furthermore, the second order conditions are satisfied for $\varepsilon_{u}>\tilde{\varepsilon}_{u}$, with $\tilde{\varepsilon}_{u} \equiv$ $c^{*} \frac{(1-\gamma)^{2} \eta_{1}\left(\mu^{*}-1\right)}{\left[1-\gamma+\mu^{*}\left(\gamma-\eta_{1}\right)\right]^{2}}\left[2-\eta_{2} /\left(1-\eta_{1}\right)\right]$. We further note $\varepsilon_{u}$ and $\varepsilon_{v}$ the degrees of concavity $\varepsilon_{u}(c)$ and $\varepsilon_{v}(d)$ evaluated at the steady state $b^{*}=1, \varepsilon_{u}^{s} \equiv \varepsilon_{u}^{s}(1)$, $\gamma \equiv \gamma(1), \eta_{1} \equiv \eta_{1}(1)$, and $\eta_{2} \equiv \eta_{2}(1)$.

We can now clarify the conditions for the multiplicity of steady states.

Proposition 3 Under Assumptions 1-4, if the following condition holds:

$$
\varepsilon_{v}<\frac{1}{c(1-\gamma)}\left(\varepsilon_{u}^{s}-\varepsilon_{u}\right)
$$

then there is a multiplicity of stationary equilibria with positive bubble. Their number is generically odd.

Proof. See Appendix.

When the monetary rule does not respond to asset prices $(\rho=0)$, the inequality (33) can be satisfied only if collateral has a small effect on the credit share (i.e. $\eta_{1}<\gamma$ ) and $\varepsilon_{u}^{s}$ is positive. ${ }^{14}$ Thinking that this is interesting to connect the multiplicity of steady states to local dynamics, we assume for the remainder of the paper:

\footnotetext{
${ }^{14}$ When $\rho=0$, the second order conditions are satisfied if $\varepsilon_{u}>\tilde{\varepsilon}_{u}$, and $\varepsilon_{u}^{s}>\tilde{\varepsilon}_{u}$ is satisfied only when $\eta_{1}<\gamma$.
} 


\section{Assumption 5}

$$
\eta_{2}<2\left(1-\eta_{1}\right)
$$

Assumption 5 ensures $\varepsilon_{u}^{s}>0$.

When the monetary rule takes into account asset prices, the inequality (33) is satisfied when the degrees of concavity $\varepsilon_{v}$ and $\varepsilon_{u}$ are small enough, when an active rule on asset prices $(\rho>0)$ is implemented and collateral has a small effect on the credit share (i.e. $\left.\eta_{1}<\gamma\right)$ or when a passive rule $(\rho<0)$ on asset prices is implemented and collateral has a large effect on the credit share (i.e. $\left.\eta_{1}>\gamma\right)$.

With the multiplicity of steady states, convergence or not to a steady state may depend on agents' expectations. ${ }^{15}$ The existence of multiple steady states may lead to a global indeterminacy, which is a source of expectation-driven fluctuations of the bubble. Interestingly, when the monetary policy rule does not depend on asset prices, this multiplicity appears under a small collateral effect (i.e. $\eta_{1}$ small with $\eta_{1}<\gamma$ ) and small degrees of concavity on utility.

Furthermore, the multiplicity of steady states raises an issue for the monetary authority concerning the choice of the rule. If the monetary authority chooses to lead an active policy for the steady state $b^{*}=1$, this does not mean that the policy would be active at the other steady states. This issue of selection is addressed for instance by Benhabib et al. (2001). Nonetheless, in our model, the multiplicity of steady states arises without introducing any bound on the monetary rule.

Illustration. The example given by Eq. (7) may fit all the requirements we impose on the function $\gamma\left(b_{t}\right)$. This is examined showing the non-emptiness of the set of parameter values implied by Assumptions $2-5$.

The function $\gamma\left(b_{t}\right)=\frac{A}{s} \exp \left(-s b_{t}\right)$, with $0<A<s(1-\epsilon)$ and $\epsilon$ sufficiently close to 0, satisfies of course Assumption 2.

In Section 3, we show that Assumption 3 rewrites $\eta_{1}\left(b_{t}\right)<1$ at the equilibrium. Note that our example of function $\gamma\left(b_{t}\right)$ satisfies this inequality for all $b_{t}$, because $\eta_{1}\left(b_{t}\right) \leq \frac{A}{s} \exp \left(-s b_{t}\right) \leq \frac{A}{s}<1$.

When $\rho>0$, the existence of a steady state with a positive bubble requires Assumption 4. With our example, we can rewrite Assumption 4 as follows:

$$
\varepsilon_{v}(0)<\frac{\rho}{1+\alpha}
$$

For $\alpha<+\infty$, the right-hand side is positive and different from zero. As a consequence, an utility function whose the degree of concavity is increasing in consumption can satisfy the above inequality (34). A possible illustration of such an utility function is provided by the following formulation:

$$
v(d)=\left(\frac{d-\delta_{0}}{1-\delta_{1}}\right)^{1-\delta_{1}}, \text { i.e. } \varepsilon_{v}(d)=\frac{\delta_{1} d}{d-\delta_{0}}
$$

\footnotetext{
${ }^{15}$ Note that, in our model, this multiplicity will be related to the local indeterminacy.
} 
We obtain $\varepsilon_{v}(0)=0$. Therefore, Assumption 4 is always verified with our example of $\gamma\left(b_{t}\right)$.

To connect the multiplicity of steady states to local dynamics, Assumption 5 must be satisfied at the normalized steady state. With our example of $\gamma\left(b_{t}\right)$, Assumption 5 is equivalent to:

$$
s(2-s)-(2+s) A \exp (-s)>0
$$

As $\exp (-s)<1, A<\frac{s(2-s)}{2+s} \equiv A_{1}$ is a sufficient condition to ensure this last inequality. As a result, if $s<2$ and $A<A_{1}$, then Assumption 5 is always satisfied.

In the following, we admit two cases for the analysis of local dynamics $\gamma>\eta_{1}$ and $\gamma<\eta_{1} . \gamma>\eta_{1}$ requires $A<\frac{s(1-s)}{\exp (-s)} \equiv A_{2}$ and $s<1$, whereas $s>1$ is a sufficient condition for $\gamma<\eta_{1}$ whatever the value of $A$.

To summarize, when $\gamma>\eta_{1}$, the non-empty set of parameter values for which Assumptions $2-5$ are always satisfied is given by $0<A<\min \left\{A_{1} ; A_{2} ; s(1-\epsilon)\right\}$ and $0<s<1$. When $\gamma<\eta_{1}, A<\min \left\{A_{1}, s(1-\epsilon)\right\}$ and $1<s<2$ is a nonempty set of parameter values for which Assumptions $2-5$ are always satisfied.

\section{Expectation-driven fluctuations and endoge- nous cycles}

This section is devoted to the existence of expectation-driven fluctuations of a rational bubble. Our explanation mainly lies in credit markets features. We will show that the steady state with a positive bubble can be locally indeterminate, and therefore expectation-driven fluctuations of the bubble can emerge. To highlight bubble fluctuations, we consider the model with a constant money growth, first when the credit share is constant, second when collateral matters. When the credit share is constant, indeterminacy always occurs under a sufficiently large degree of utility concavity. In contrast, when the credit share depends on asset holdings, we obtain a new interesting result: indeterminacy also occurs under a sufficiently small degree of utility concavity and arbitrarily small credit market distortions. In the next section, we enrich the model with monetary rules based on inflation forecast targeting and on asset prices to study the (de-)stabilizing role of monetary policy.

\subsection{Local dynamics: preliminaries}

To derive our different results, we start by linearizing the dynamic equation (26) around the steady state $b^{*}=1$ to obtain the characteristic polynomial.

\section{Assumption 6}

$$
\varepsilon_{v} \neq \frac{1-\gamma+\mu^{*}\left(\gamma-\eta_{1}\right) \frac{1}{1+\alpha}}{1-\gamma+\mu^{*}\left(\gamma-\eta_{1}\right)} \equiv \bar{\varepsilon}_{v}
$$


Using this assumption, we get:

Lemma 3 Let

$$
\bar{\varepsilon}_{u} \equiv-c^{*}(1-\gamma) \frac{\mu^{*}\left(\gamma-\eta_{1}\right)}{1-\gamma+\mu^{*}\left[\gamma-\eta_{1}\right]} \frac{1 / \gamma}{1+\alpha}
$$

Under Assumptions 1-6, the characteristic polynomial, evaluated at the steady state $b^{*}=1$, is defined by $P(X) \equiv X^{2}-T X+D=0$, where:

$$
\begin{aligned}
D= & \frac{1}{\bar{\varepsilon}_{v}-\varepsilon_{v}} \frac{\eta_{1}}{c^{*}(1-\gamma)}\left(\varepsilon_{u}-\bar{\varepsilon}_{u}\right) \equiv D\left(\varepsilon_{v}\right) \\
T= & \frac{1}{\bar{\varepsilon}_{v}-\varepsilon_{v}}\left\{\frac{\varepsilon_{u}}{c^{*}(1-\gamma)}-\eta_{1} \varepsilon_{v}+\frac{(1-\gamma)}{1-\gamma+\mu^{*}\left(\gamma-\eta_{1}\right)}[1-\right. \\
& \left.\left.\left(\mu^{*}-1\right) \eta_{1}\left(2-\frac{\eta_{2}}{1-\eta_{1}}\right)\right]+\frac{\mu^{*}\left(\gamma-\eta_{1}\right)}{1-\gamma+\mu^{*}\left(\gamma-\eta_{1}\right)} \frac{1-\rho+\eta_{1} / \gamma}{1+\alpha}\right\} \\
& \equiv T\left(\varepsilon_{v}\right)
\end{aligned}
$$

Proof. See Appendix.

As in Grandmont et al. (1998), we study the variations of the trace $T\left(\varepsilon_{v}\right)$ and the determinant $D\left(\varepsilon_{v}\right)$ in the $(T, D)$ plane as one of the parameters of interest, namely $\varepsilon_{v}$, is made to vary continuously in its admissible range $(0,+\infty)$ (see Figures 1 and 2). The locus $\Sigma \equiv\left\{\left(T\left(\varepsilon_{v}\right), D\left(\varepsilon_{v}\right)\right): \varepsilon_{v} \geq 0\right\}$ describes a part of a line that we call the $\Sigma$-line.

Along the line $(A C)$, one eigenvalue is equal to $1(D=T-1)$. Along the line $(A B)$, one eigenvalue is equal to $-1(D=-T-1)$. Along the segment $[B C](|T|<2, D=1)$, the characteristic roots are complex conjugates with modulus equal to 1 . These lines divide the space $(T, D)$ into three different types of regions. Therefore, inside the triangle $A B C$, the steady state is a sink, i.e. locally indeterminate $(|T|<1+D$ and $D<1)$. It is a saddle point if $(T, D)$ lies on the right or left sides of both the lines $(A B)$ and $(A C)(|1+D|<|T|)$. It is a source otherwise.

A (local) bifurcation arises when at least one eigenvalue crosses the unit circle, that is, when the $\Sigma$-line crosses one of the loci $(A B),(A C)$ or $[B C]$. According to the changes of the bifurcation parameter, a pitchfork bifurcation (generically) emerges when the $\Sigma$-line crosses $(A C)$, as $\varepsilon_{v}$ goes through $\varepsilon_{v}^{s} \cdot{ }^{16}$ A flip bifurcation occurs when the $\Sigma$-line crosses $(A B)$, as $\varepsilon_{v}$ goes through $\varepsilon_{v}^{f}$. Finally, a Hopf bifurcation (generically) arises when the $\Sigma$-line crosses the segment $[B C]$, as $\varepsilon_{v}$ goes through $\varepsilon_{v}^{h} \cdot{ }^{17}$

The $\Sigma$-line has a slope $S$ given by:

$$
S=\frac{\frac{\eta_{1}}{c^{*}(1-\gamma)}\left(\varepsilon_{u}-\bar{\varepsilon}_{u}\right)}{\frac{\varepsilon_{u}}{c^{*}(1-\gamma)}-\eta_{1} \frac{\bar{\varepsilon}_{u}}{c^{*}(1-\gamma)}+\frac{(1-\gamma)\left[1-\eta_{1}-\eta_{1}\left(\mu^{*}-1\right)\left(2-\frac{\eta_{2}}{1-\eta_{1}}\right)\right]}{1-\gamma+\mu^{*}\left(\gamma-\eta_{1}\right)}+\frac{1-\eta_{1}-\rho}{1+\alpha} \frac{\mu^{*}\left(\gamma-\eta_{1}\right)}{1-\gamma+\mu^{*}\left(\gamma-\eta_{1}\right)}}
$$

\footnotetext{
${ }^{16}$ Indeed, we have (generically) an odd number of steady states (see Section 4.2).

${ }^{17}$ The bifurcation values of $\varepsilon_{v}, \varepsilon_{v}^{s}, \varepsilon_{v}^{f}$ and $\varepsilon_{v}^{h}$, are given in Appendix.
} 
We further note that the $\Sigma$-line is characterized by the endpoint $(T(+\infty), D(+\infty))$ $\equiv\left(\eta_{1}, 0\right)$ and the starting point given by:

$$
\begin{aligned}
T(0)= & \frac{1}{\bar{\varepsilon}_{v}}\left\{\frac{\varepsilon_{u}}{c^{*}(1-\gamma)}+\frac{(1-\gamma)}{1-\gamma+\mu^{*}\left(\gamma-\eta_{1}\right)}\left[1-\left(\mu^{*}-1\right) \eta_{1}\left(2-\frac{\eta_{2}}{1-\eta_{1}}\right)\right]\right. \\
& \left.+\frac{\mu^{*}\left(\gamma-\eta_{1}\right)}{1-\gamma+\mu^{*}\left(\gamma-\eta_{1}\right)} \frac{1-\rho+\eta_{1} / \gamma}{1+\alpha}\right\} \\
D(0)= & \frac{1}{\bar{\varepsilon}_{v}}\left[\frac{\eta_{1}}{c^{*}(1-\gamma)}\left(\varepsilon_{u}-\bar{\varepsilon}_{u}\right)\right] \\
\text { with } \quad & 1-T(0)+D(0)=\frac{1}{\bar{\varepsilon}_{v}} \frac{\left(1-\eta_{1}\right)}{c^{*}(1-\gamma)}\left(\varepsilon_{u}^{s}-\varepsilon_{u}\right) \\
\text { and } \quad & \varepsilon_{u}^{s} \equiv c^{*} \frac{1-\gamma}{1-\eta_{1}}\left\{\eta_{1} \frac{(1-\gamma)\left(\mu^{*}-1\right)}{1-\gamma+\mu^{*}\left(\gamma-\eta_{1}\right)}\left(2-\frac{\eta_{2}}{1-\eta_{1}}\right)\right. \\
& \left.+\frac{\rho}{1+\alpha} \frac{\mu^{*}\left(\gamma-\eta_{1}\right)}{1-\gamma+\mu^{*}\left(\gamma-\eta_{1}\right)}\right\}
\end{aligned}
$$

\subsection{Fluctuations of a bubble}

As already underlined, to prove the existence of bubble fluctuations, the monetary policy is assumed to neither depend on inflation forecasts, nor on asset prices (i.e. $\alpha=\rho=0$ ). Moreover, to highlight the role played by collateral on the credit share, we begin by analyzing the case of a constant credit share (i.e. $\left.\eta_{1}=\eta_{2}=0\right)$.

\subsubsection{Constant credit share}

When $\gamma$ is constant (i..e. $\eta_{1}=\eta_{2}=0$ ), the trace $T\left(\varepsilon_{v}\right)$ and the determinant $D\left(\varepsilon_{v}\right)$ simplify to:

$$
T\left(\varepsilon_{v}\right)=1+\frac{1}{1-\varepsilon_{v}}\left(\frac{\varepsilon_{u}}{c^{*}(1-\gamma)}+\varepsilon_{v}\right) \quad \text { and } \quad D\left(\varepsilon_{v}\right)=0
$$

As a consequence, the slope of the $\Sigma$-line is equal to 0 .

Since $T\left(\varepsilon_{v}\right)$ is strictly increasing in $\varepsilon_{v}$ and $T(0)>1$, when $\varepsilon_{v}$ varies from 0 to $+\infty,\left(T\left(\varepsilon_{v}\right), D\left(\varepsilon_{v}\right)\right)$ moves on the $\Sigma$-line, which lies on the horizontal axis, starting from the right side of $(A C)$, crossing $\pm \infty$ when $\varepsilon_{v}$ goes through 1 , then $(A B)$ as $\varepsilon_{v}=\varepsilon_{v}^{f}$, and ending at $(0,0)$ (see Figure 1 ).

Proposition 4 Let $\gamma$ be constant (i.e. $\eta_{1}=0$ and $\eta_{2}=0$ ). Under Assumptions 1-6, the following generically holds:

The bubbly steady state is a saddle for $\varepsilon_{v}<\varepsilon_{v}^{f}$, undergoes a flip bifurcation for $\varepsilon_{v}=\varepsilon_{v}^{f}$, and is a sink for $\varepsilon_{v}>\varepsilon_{v}^{f}$.

This proposition shows that persistent fluctuations due to self-fulfilling expectations could emerge around the bubbly steady state. Expectation-driven 


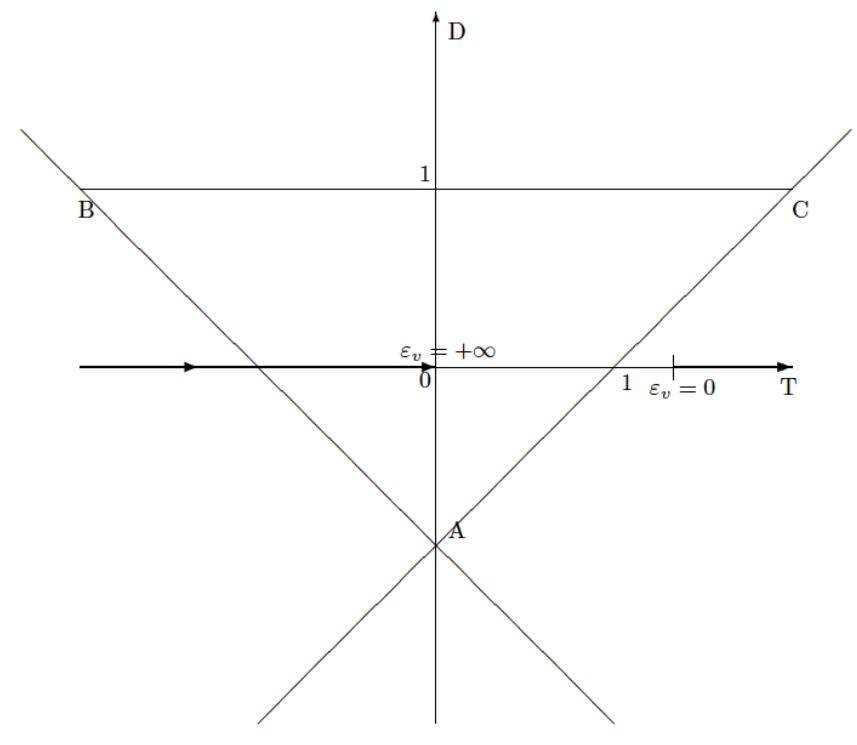

Figure 1: Constant credit share

fluctuations and two-period cycles occur under a significant income effect. This confirms the well-known result obtained by Grandmont $(1985,1986)$ even if there are two assets in our model, a bubble and money held for a transaction motive. The economic intuition is the following. If households expect an increase in inflation from period $t$ to $t+1$, then they reduce their first-period consumption, and increase their global savings, $b_{t}+m_{t}$. As $\gamma$ is constant, portfolio choice is unchanged. However, households reduce their second-period consumption implying a decrease in the return on savings. ${ }^{18}$ It follows a raise in inflation and a reduction of the bubble value. Thus, the beliefs are self-fulfilling, and expectation-driven fluctuations emerge.

\subsubsection{The role of collateral}

We analyze now the role of collateral on expectation-driven fluctuations taking into account that $\eta_{1}$ is not too large. ${ }^{19}$ However, we admit either $\eta_{1}<\gamma$ or $\eta_{1}>\gamma$. In the first case, collateral has a small effect on the credit share, while collateral has a large effect in the second one.

To identify the indeterminacy properties of the steady state $b^{*}=1$, we study how the $\Sigma$-line evolves in the $(T, D)$ plane in function of $\eta_{1}$. We assume

\footnotetext{
${ }^{18}$ From the binding cash-in-advance constraint and the money growth factor (Eq. (15)), we obtain $\gamma d_{t+1}=\left(\mu^{*} / \pi_{t+1}\right) m_{t}$ when $\eta_{1}=0$. We can see if $d_{t+1}$ is decreasing and $m_{t}$ increasing, $\mu^{*} / \pi_{t+1}$ must decrease.

${ }^{19}$ When $\eta_{1}$ is large enough, results are qualitatively similar except that Hopf bifurcations are possible.
} 
Assumption $7 \eta_{1}$ is not too large, such that:

$$
1>\frac{\eta_{1}}{1-\eta_{1}}\left(\mu^{*}-1\right)\left(2-\frac{\eta_{2}}{1-\eta_{1}}\right)
$$

Assumption 7 appears reasonable since it implies a not excessively large effect of collateral on the credit share.

From direct inspection of the different bifurcation values $\varepsilon_{v}^{f}, \varepsilon_{v}^{h}$ and $\varepsilon_{v}^{s}$, we deduce that under Assumptions 1 - 7:

$$
\varepsilon_{v}^{s}<\varepsilon_{v}^{h}<\varepsilon_{v}^{f}
$$

The inequality (44) means that $T\left(\varepsilon_{v}\right)$ is increasing in $\varepsilon_{v}$. Hence, $\left(T\left(\varepsilon_{v}\right), D\left(\varepsilon_{v}\right)\right)$ goes rightward crossing $\pm \infty$ when $\varepsilon_{v}$ goes through $\bar{\varepsilon}_{v}$.

Let $S_{C}>0$ be the critical value of $S$ such that the $\Sigma$-line goes through the point $C .{ }^{20}$ When $\eta_{1}<\gamma$, it can easily be shown from Eq. (38) and the inequality (44) that the $\Sigma$-line has a slope in $\left(0, S_{C}\right)$ under Assumptions $1-7$. In addition, the $\Sigma$-line starts inside the triangle $A B C$ for $\tilde{\varepsilon}_{u}<\varepsilon_{u}<\varepsilon_{u}^{s}$, then crosses $(A C)$ as $\varepsilon_{v}=\varepsilon_{v}^{s}$, goes inside the triangle $A B C$ by crossing $(A B)$ as $\varepsilon_{v}=\varepsilon_{v}^{f}$, and ends at $(T(+\infty), D(+\infty))$ on the horizontal axis. ${ }^{21}$ When $\varepsilon_{u}>\varepsilon_{u}^{s}$, the $\Sigma$-line starts outside the triangle $A B C$, on the right side of $(A C)$ (see Figure 2).

The $\Sigma$-line still has a slope $S$ in $\left(0, S_{C}\right)$ when $\eta_{1}>\gamma$ and $\varepsilon_{u}>\bar{\varepsilon}_{u}$, but a slope $S$ in $\left(S_{B}, 0\right)$ when $\eta_{1}>\gamma$ and $\varepsilon_{u}<\bar{\varepsilon}_{u}$, where $S_{B}<0$ is the critical value of $S$ such that the $\Sigma$-line goes through the point $B .{ }^{22}$ Since $T\left(\varepsilon_{v}\right)$ is increasing in $\varepsilon_{v}$, the $\Sigma$-line points upwards (downwards) to the right when $\varepsilon_{u}>\bar{\varepsilon}_{u}\left(\varepsilon_{u}<\bar{\varepsilon}_{u}\right)$. Moreover, the $\Sigma$-line always starts on the right side of (AC) ${ }^{23}$ Afterwards, the $\Sigma$-line goes inside the triangle $A B C$ by crossing $(A B)$ as $\varepsilon_{v}=\varepsilon_{v}^{f}$, and ends at $(T(+\infty), D(+\infty))$ on the horizontal axis (see Figure 2).

Proposition 5 ( $\eta_{1}>0$ : collateral matters) Under Assumptions 1-7, the following generically holds:

1. If $\eta_{1}<\gamma$ and $\varepsilon_{u} \in\left(\tilde{\varepsilon}_{u}, \varepsilon_{u}^{s}\right)$ : the steady state is a sink for $\varepsilon_{v}<\varepsilon_{v}^{s}$, undergoes a pitchfork bifurcation for $\varepsilon_{v}=\varepsilon_{v}^{s}$, is a saddle for $\varepsilon_{v} \in\left(\varepsilon_{v}^{s}, \varepsilon_{v}^{f}\right)$, undergoes a flip bifurcation for $\varepsilon_{v}=\varepsilon_{v}^{f}$, is a sink for $\varepsilon_{v}>\varepsilon_{v}^{f}$.

2. If $\eta_{1}<\gamma$ and $\varepsilon_{u}>\varepsilon_{u}^{s}$ or if $\eta_{1}>\gamma$ : the steady state is a saddle for $\varepsilon_{v}<\varepsilon_{v}^{f}$, undergoes a flip bifurcation for $\varepsilon_{v}=\varepsilon_{v}^{f}$, is a sink for $\varepsilon_{v}>\varepsilon_{v}^{f}$.

Proposition 5 establishes that local indeterminacy and endogenous cycles could occur under sufficiently large income effects $\left(\varepsilon_{v}>\varepsilon_{v}^{f}\right)$, but also more surprisingly under sufficiently small income effects $\left(\varepsilon_{v}<\varepsilon_{v}^{s}\right)$. This requires that collateral matters, but has a sufficiently small effect on the credit share (i.e. $\left.\eta_{1}<\gamma\right)$. Interestingly, this is also associated to the multiplicity of steady states

\footnotetext{
${ }^{20} 0<S_{C}=1 /\left(2-\eta_{1}\right)<1$.

${ }^{21}$ When $\eta_{1}<\gamma, 1-T(0)-D(0)>0$ is satisfied for $\tilde{\varepsilon}_{u}<\varepsilon_{u}<\varepsilon_{u}^{s}$.

$22-1<S_{B}=-1 /\left(2+\eta_{1}\right)<0$.

${ }^{23}$ When $\eta_{1}>\gamma, \varepsilon_{u}^{s}<\tilde{\varepsilon}_{u}<\varepsilon_{u}$ for $\rho=0$. Hence $1-T(0)-D(0)<0$.
} 


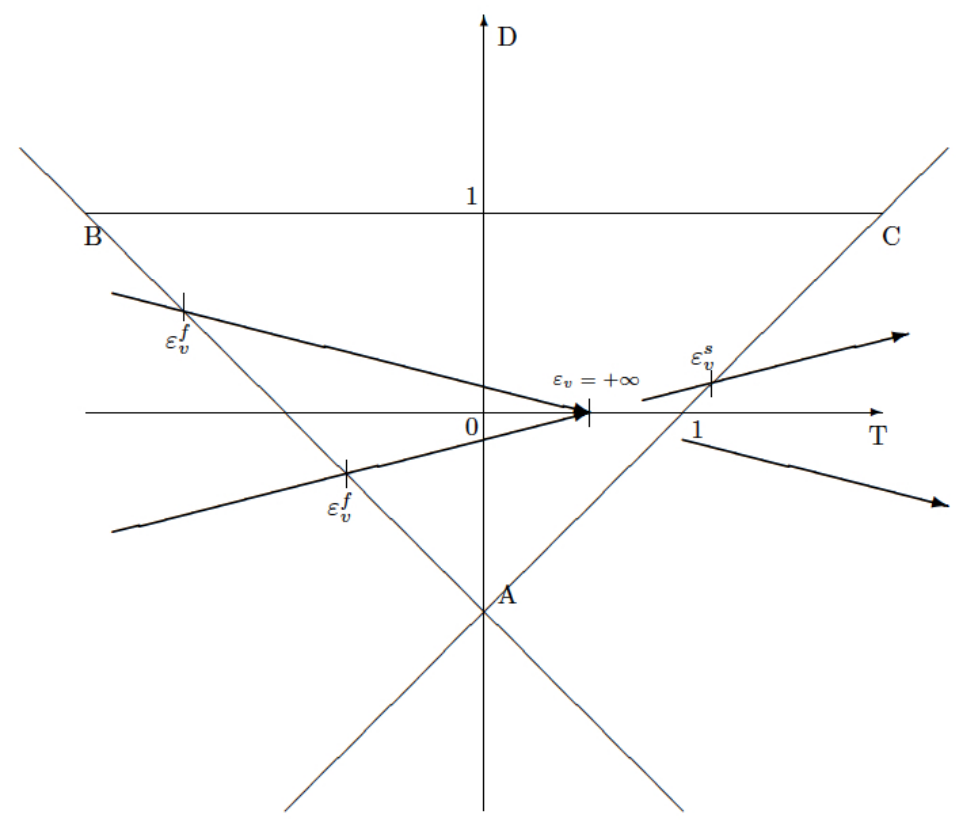

Figure 2: The role of collateral

(see Proposition 3). The intuition is the following. If households expect an increase in inflation from period $t$ to $t+1$, then they reduce their first-period consumption, and increase their savings if the income effect dominates. The intuition is similar to the previous one with a constant $\gamma$. However, when income effects are small, this mechanism is no more relevant. As collateral now matters, a change in the portfolio structure takes place: an expected inflation rise generates now a portfolio effect, which leads to expectation-driven fluctuations when income effects are small. Because the return on money is lower than the return on asset paper, households reallocate savings from monetary $m_{t}$ to non-monetary savings, i.e. the bubble $b_{t}$. The amount of collateral increases. Hence, households consume less by cash, which implies that the return on money decreases. An effective rise in inflation takes place, and expectations are self-fulfilling.

We have shown that a rational bubble could experience endogenous fluctuations driven by the volatility of agents' expectations. We turn now to the analysis of the (de-)stabilizing role of monetary policy.

\section{The (de-)stabilizing role of monetary policy}

The question we address now is: can a monetary policy protect the economy against such bubble fluctuations driven by the volatility of agents' expectations? 
The issue has been essentially explored within economies without collateral and portfolio choice (Grandmont (1985, 1986), Sorger (2005)). While Grandmont $(1985,1986)$ describes as stabilizing a monetary policy coordinating expectations, a monetary policy is stabilizing in our framework as soon as it reduces the range of parameter values for which expectation-driven fluctuations occur. In line with Sorger (2005), we first study an inflation forecast targeting rule which responds only to the expected inflation $(\alpha \neq 0$ and $\rho=0)$. Note that such a rule is of interest since it seems to be relevant to describe the US monetary policy than a rule based on observed inflation (Bernanke (2010)). Second, we analyze a rule taking into account asset prices. Considering such a monetary rule may be appropriate in an economy in which a bubble could persist and experience fluctuations. Thus, we contribute to the debate initiated by Bernanke and Gertler (1999, 2001), whether central banks should react to movements in asset prices. We extend the inflation targeting rule by including directly asset price level $(\alpha \neq 0$ and $\rho \neq 0)$. Our findings mitigate the conclusions issued by Bernanke and Gertler (1999, 2001), Gilchrist and Leahy (2002), and more recently Carlstrom and Fuerst (2007). Compared with the first two ones, we show that such a rule may have a significant effect on the macroeconomic stability. Unlike to Calstrom and Fuerst (2007), such a rule stabilizes fluctuations.

To do this, we examine how local dynamics are altered by the implementation of monetary policy. As previously, our analysis focuses on a not too large value of $\eta_{1}$.

\subsection{Inflation forecast targeting}

Referring to Sorger (2005), we start by analyzing the stabilizing role of inflation forecast targeting on the emergence of fluctuations. However, we consider a model with two assets, a bubble and money held for a transaction motive, and most importantly in which collateral matters. We will see that this last feature may reverse the conclusion obtained by Sorger (2005) that an active rule on inflation forecasts tends to destabilize.

The monetary authority conducts a monetary rule given by Eq. (15) with $\rho=0$ :

$$
\mu_{t}=\mu^{*}\left(\frac{\pi_{t+1}}{\mu^{*}}\right)^{-\alpha}, \quad \text { with } \alpha \geq-1 .
$$

The purpose is to evaluate whether inflation forecast targeting stabilizes or rather destabilizes expectation-driven fluctuations around the bubbly steady state. As in the previous section, focusing on the geometrical elements, we can easily check that under Assumptions $1-7$, the slope $S$ is always positive when $\eta_{1}<\gamma$ and could be negative when $\eta_{1}>\gamma$.

For any value of $\alpha$, when $\eta_{1}<\gamma$, the $\Sigma$-line has a slope between $\left(0, S_{C}\right)$ and starts inside the triangle $A B C$ for $\tilde{\varepsilon}_{u}<\varepsilon_{u}<\varepsilon_{u}^{s}$, then crosses $(A C)$ as $\varepsilon_{v}=\varepsilon_{v}^{s}$, goes inside the triangle $A B C$ by crossing $(A B)$ as $\varepsilon_{v}=\varepsilon_{v}^{f}$, and ends at $(T(+\infty), D(+\infty))$ on the horizontal axis. When $\varepsilon_{u}>\varepsilon_{u}^{s}$, the $\Sigma$-line starts 
on the right side of $(A C)$. These configurations are very similar to Proposition 5 .

When $\eta_{1}>\gamma$, to keep things as simple as possible, we assume:

Assumption 8 Let $\alpha^{A}$ and $\alpha^{B}$ be given in Appendix by Eqs. (55) and (56).

$$
\alpha>\tilde{\alpha}, \text { with } \tilde{\alpha}=\max \left\{\alpha^{A}, \alpha^{B}\right\}
$$

We can note that $\tilde{\alpha}<0$ may be close to -1 , especially if the difference between $\eta_{1}$ and $\gamma$ is not too large or under small distortions ( $\eta_{1}$ and $\gamma$ close to zero). Hence, this assumption does not seem to be restrictive.

Again, the configurations are quite similar to Proposition 5 under Assumptions $1-8$. Indeed, for $\alpha>\tilde{\alpha}$, the inequality (44) is satisfied, and when $\varepsilon_{u} \geq \bar{\varepsilon}_{u}$ $\left(\varepsilon_{u}<\bar{\varepsilon}_{u}\right)$, the $\Sigma$-line has a slope $S$ between $\left(0, S_{C}\right)$ (between $\left(S_{B}, 0\right)$ ), always starts on the right side of $(A C)$, goes inside the triangle $A B C$ by crossing $(A B)$ between $A$ and $B$ as $\varepsilon_{v}=\varepsilon_{v}^{f}$, and ends at $(T(+\infty), D(+\infty))$.

To summarize, when $\eta_{1}<\gamma$, local indeterminacy occurs if $\varepsilon_{v}<\varepsilon_{v}^{s}$ or if $\varepsilon_{v}>\varepsilon_{v}^{f}$, and when $\eta_{1}>\gamma$, if $\varepsilon_{v}>\varepsilon_{v}^{f}$. Hence, to analyze the role of the monetary policy, we only need to examine how these critical bifurcation values, $\varepsilon_{v}^{f}$ and $\varepsilon_{v}^{s}$, vary in function of $\alpha$. Indeed, these variations give a picture of the role of monetary policy on local indeterminacy.

Lemma $4(\alpha \neq 0$ and $\rho=0)$

Under Assumptions 1-7, the effects of monetary policy on the bifurcation values are given by the following derivatives:

1. When $\eta_{1}<\gamma, \frac{d \varepsilon_{v}^{s}}{d \alpha}=0$ and $\frac{d \varepsilon_{v}^{f}}{d \alpha}<0$.

2. When $\eta_{1}>\gamma, \frac{d \varepsilon_{v}^{f}}{d \alpha}>0$.

Proof. See Appendix.

If $\eta_{1}<\gamma$, the higher $\alpha$ is, the lower $\varepsilon_{v}^{f}$ is. On the other hand, $\varepsilon_{v}^{s}$ does not depend on $\alpha$ (see Figure 3(a)). ${ }^{24}$ Hence, we can deduce the (de-)stabilizing role of an inflation targeting monetary policy.

Proposition 6 Under Assumptions 1-7, the following generically holds when $\eta_{1}<\gamma$ :

1. The more active the monetary policy is ( $\alpha$ higher), the more destabilizing it is in the neighborhood of the steady state $b^{*}$, for large income effects.

2. A more active monetary policy has no destabilizing or stabilizing effects in the neighborhood of the steady state $b^{*}$, for small income effects.

\footnotetext{
${ }^{24}$ Figure $3(a)$ qualitatively illustrates the case $\varepsilon_{u} \in\left(\tilde{\varepsilon}_{u}, \varepsilon_{u}^{s}\right)$. For $\varepsilon_{u}>\varepsilon_{u}^{s}$, the figure would be qualitatively the same but without the line $\varepsilon_{v}^{s}$.
} 


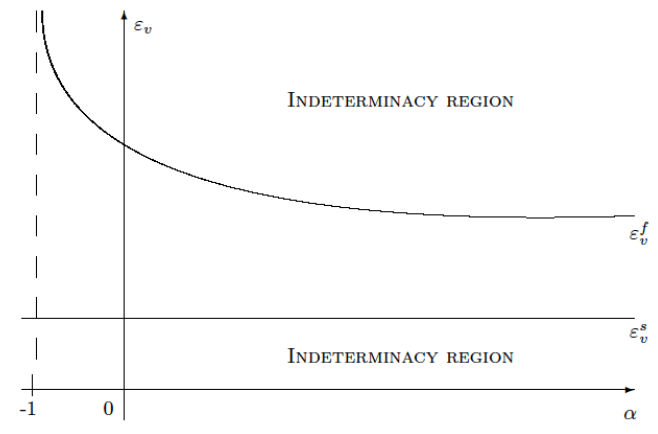

(a) $\eta_{1}<\gamma$

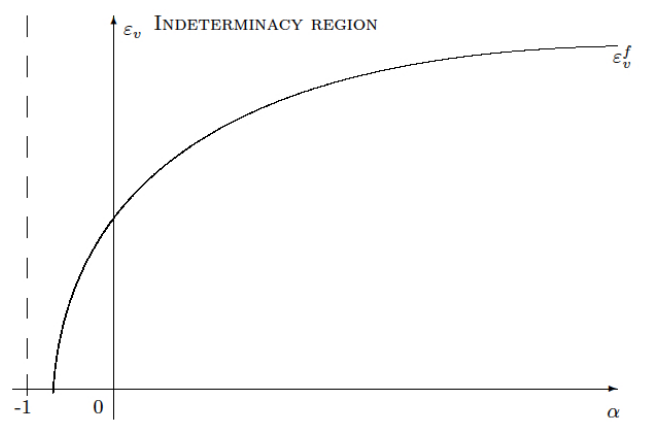

(b) $\eta_{1}>\gamma$

Figure 3: Stabilizing role of inflation forecast targeting

This proposition suggests that when $\varepsilon_{v}>\varepsilon_{v}^{f}$, an active inflation forecast targeting promotes the emergence of expectation-driven fluctuations, while a passive policy may rule out it. This is in accordance with Sorger (2005), even if we assume that the monetary transfer is distributed at the first period of life and there is a portfolio choice. However, such a monetary policy does not (de-)stabilize fluctuations which occur for small $\varepsilon_{v}$. This also means that a monetary policy, which responds only to expected inflation, has no impact on the multiplicity of steady states.

We focus now on the case $\eta_{1}>\gamma$, we remind that local indeterminacy requires $\varepsilon_{v}>\varepsilon_{v}^{f}$. From Lemma 4 , we deduce that the higher $\alpha$ is, the larger $\varepsilon_{v}^{f}$ is (see Figure $3(b)$ ).

The next proposition summarizes the role of an inflation targeting monetary policy when $\eta_{1}>\gamma$ :

Proposition 7 Under Assumptions 1-8, the following generically holds when $\eta_{1}>\gamma$ : the more active the monetary policy is, the more stabilizing it is in the neighborhood of the steady state $b^{*}$, for large income effects.

This proposition means that, for large income effects, a sufficiently active monetary policy hardens the condition on $\varepsilon_{v}$, which guarantees local indeterminacy. An active inflation forecast targeting could stabilize the fluctuations of the rational bubble. This mitigates the clear-cut conclusion given by Sorger (2005), i.e. an active inflation targeting is preferable to an active inflation forecast targeting in terms of stabilization.

To summarize, the stabilizing role of active inflation forecast targeting depends on the sensibility of the credit share with respect to collateral. A sufficiently large sensitivity of credit share to collateral is the source of the stabilizing role of an active monetary policy. However, such a monetary rule has no effect on fluctuations occurring for small income effects. 


\subsection{Monetary rule with asset price level}

To answer the question addressed in particular by Bernanke and Gertler (2001) "Should central banks respond to movements in asset prices?", we enrich the inflation forecast targeting rule. The money growth factor also responds to asset price deviation from the stationary value $b^{*}$ :

$$
\mu_{t}=\mu^{*}\left(\frac{\pi_{t+1}}{\mu^{*}}\right)^{-\alpha}\left(\frac{b_{t}}{b^{*}}\right)^{-\rho}, \quad \text { with } \alpha \geq-1, \rho \geq-1 .
$$

We examine whether taking into account asset prices in the monetary rule significantly alters the (de-)stabilizing role of monetary policy. Thus, we extend our previous analysis to changes in asset prices for a given value of $\alpha$.

When $\rho$ increases from -1 to $+\infty$, the location of the $\Sigma$-line in the plane $\left(T\left(\varepsilon_{v}\right), D\left(\varepsilon_{v}\right)\right)$ differs from the previous analysis. ${ }^{25}$

We begin with $\gamma>\eta_{1}$. Let $S_{\rho=0}$ be the slope of $\Sigma$-line when $\rho=0$, which is the slope studied in the previous section when the monetary policy does not respond to asset prices (Section 6.1). When $\rho=-1$, the configuration is quite similar to Proposition 5. Indeed, the slope $S$ of $\Sigma$-line belongs to $\left(0, S_{\rho=0}\right)$ (see Eq. (38)) and $\varepsilon_{v}^{s}<\varepsilon_{v}^{h}<\varepsilon_{v}^{f}$. However, under some parameter restrictions, $\varepsilon_{v}^{s}$ is negative. As a result, when $\rho=-1$, the $\Sigma$-line starts on the left side of $(A C),{ }^{26}$ goes rightwards, then goes inside the triangle $A B C$ by crossing $(A B)$ between the points $A$ and $B$ as $\varepsilon_{v}=\varepsilon_{v}^{f}$, and ends at $(T(+\infty), D(+\infty))$ on the horizontal axis. Afterwards, as the slope $S$ of the $\Sigma$-line is increasing in $\rho$, the $\Sigma$ line makes a counterclockwise rotation around the endpoint $(T(+\infty), D(+\infty))$ when $\rho$ increases. Thus, the $\Sigma$-line first goes through $C$ (i.e. $\varepsilon_{v}^{s}=\varepsilon_{v}^{h}$ ), second through $A$ (i.e. $\varepsilon_{v}^{s}=\varepsilon_{v}^{f}$ ), then through $B$ (i.e. $\varepsilon_{v}^{f}=\varepsilon_{v}^{h}$ ), and becomes flat close to zero.

We focus now on $\eta_{1}>\gamma$. As for the previous case, we study the location of the $\Sigma$-line in the $(T, D)$ plane when $\rho=-1$. In contrast to $\gamma>\eta_{1}$, the configurations are quite different to Proposition 5 under some parameter restrictions. ${ }^{27}$

When $\eta_{1}>\gamma$ and $\varepsilon_{u}<\bar{\varepsilon}_{u}$, the $\Sigma$-line also makes a counterclockwise rotation around the endpoint $(T(+\infty), D(+\infty))$ when $\rho$ increases. $^{28}$ However, for $\rho=$ -1 , the slope $S$ of $\Sigma$-line is between $\left(0, S_{C}\right)$ (see Eq. (38)) and $\varepsilon_{v}^{f}<0<\varepsilon_{v}^{h}<$ $\varepsilon_{v}^{s}$ under some parameter restrictions. This means that $T\left(\varepsilon_{v}\right)$ and $D\left(\varepsilon_{v}\right)$ are decreasing in $\varepsilon_{v}$. As a consequence, when $\rho=-1$, the $\Sigma$-line starts on the left side of $(A B)$, goes leftwards, then goes inside the triangle $A B C$ by crossing $(A C)$ between the points $A$ and $C$ as $\varepsilon_{v}=\varepsilon_{v}^{s}$, and ends at $(T(+\infty), D(+\infty))$ on the horizontal axis. Afterwards, as the $\Sigma$-line makes a counterclockwise rotation when $\rho$ increases, the $\Sigma$-line goes first through $C$ (i.e. $\varepsilon_{v}^{s}=\varepsilon_{v}^{h}$ ), second through $A$ (i.e. $\varepsilon_{v}^{s}=\varepsilon_{v}^{f}$ ), then through $B$ (i.e. $\varepsilon_{v}^{f}=\varepsilon_{v}^{h}$ ), and becomes flat close to zero, as $\rho$ increases.

When $\eta_{1}>\gamma$ and $\varepsilon_{u} \geq \bar{\varepsilon}_{u}$, the configuration is still different to Proposition 5 for $\rho=-1$. Indeed, the slope $S$ is between $\left(S_{B}, 0\right)$ for $\rho=-1$ and $\varepsilon_{v}^{f}<0<\varepsilon_{v}^{h}<$

\footnotetext{
${ }^{25}$ Obviously, for $\rho=0$, Propositions 6 and 7 apply.

${ }^{26}$ When $\rho=-1$, the configuration with $\varepsilon_{v}^{s}>0$ is quite similar to $\varepsilon_{v}^{s}<0$, except that the $\Sigma$-line starts inside the triangle $A B C$. However, as regards the stabilizing virtues of monetary
} 


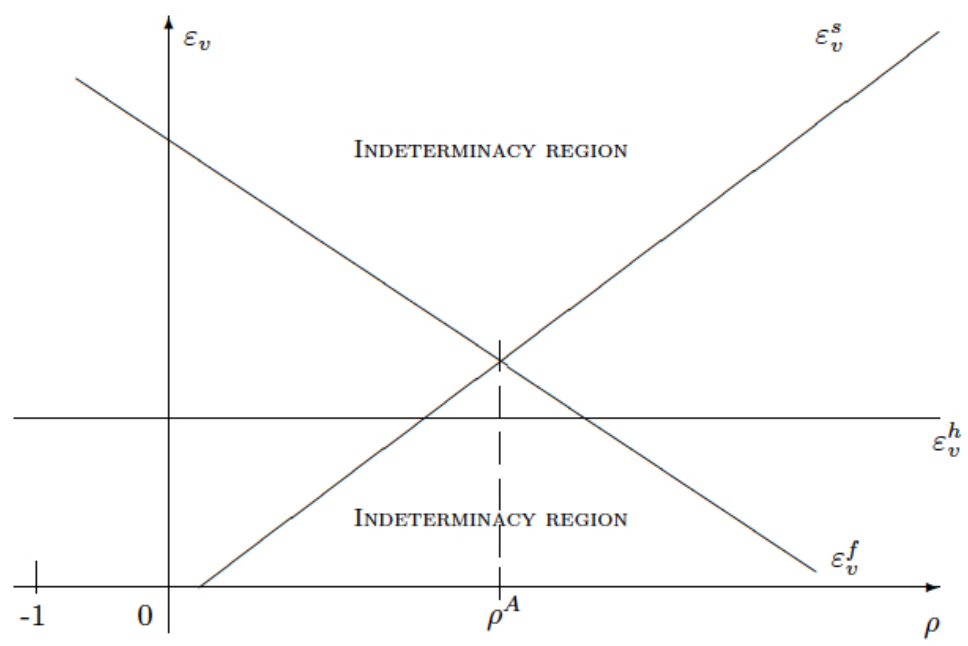

Figure 4: Stabilizing role of monetary policy with asset prices when $\eta_{1}<\gamma$

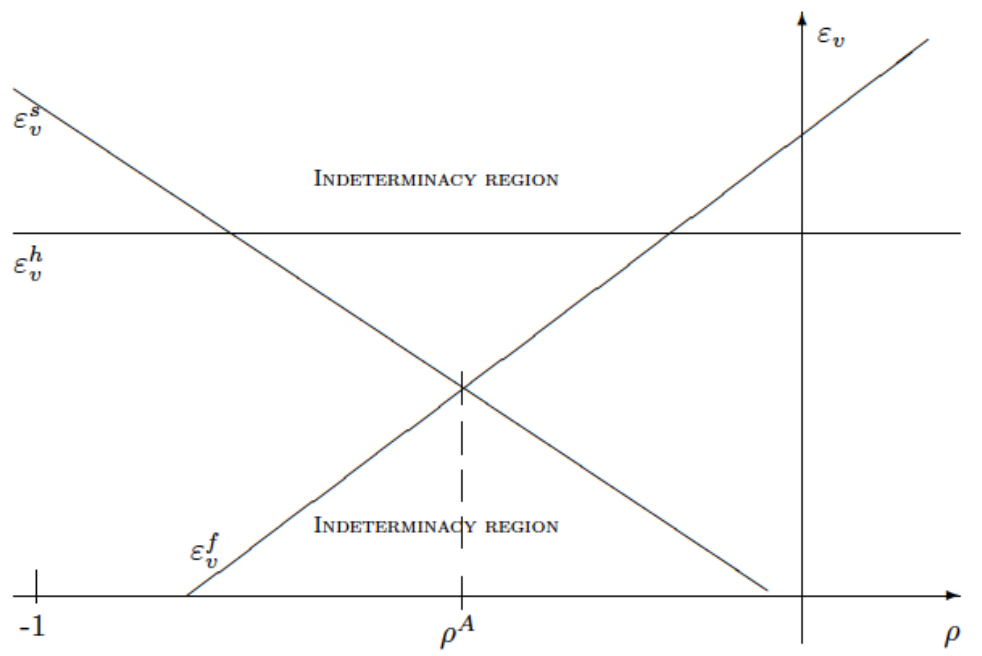

Figure 5: Stabilizing role of monetary policy with asset prices when $\eta_{1}>\gamma$ and $\varepsilon_{u}<\bar{\varepsilon}_{u}$.

policy, our results are the same qualitatively.

${ }^{27}$ Figures 5 and 6 depict the configuration where $\rho^{A}>-1$, where $\rho^{A}$ is defined by $\varepsilon_{v}^{f}=\varepsilon_{v}^{s}$.

${ }^{28}$ Indeed, when $\eta_{1}>\gamma$ and $\varepsilon_{u}<\bar{\varepsilon}_{u}, S$ is increasing in $\rho$. 
$\varepsilon_{v}^{s}$ under some parameter restrictions (see Eq. (38)). This means that $T\left(\varepsilon_{v}\right)$ is decreasing in $\varepsilon_{v}$, and $D\left(\varepsilon_{v}\right)$ is increasing in $\varepsilon_{v}$. As a result, when $\rho=-1$, the $\Sigma$-line starts on the left side of $(A B)$, goes leftwards, then goes inside the triangle $A B C$ by crossing $(A C)$ between the points $A$ and $C$ as $\varepsilon_{v}=\varepsilon_{v}^{s}$, and ends at $(T(+\infty), D(+\infty))$ on the horizontal axis. Then, as the slope $S$ is decreasing in $\rho$, the $\Sigma$-line makes a clockwise rotation when $\rho$ increases. Thus, the $\Sigma$-line goes first through $B$ (i.e. $\varepsilon_{v}^{f}=\varepsilon_{v}^{h}$ ), second through $A$ (i.e. $\varepsilon_{v}^{s}=\varepsilon_{v}^{f}$ ), then through $C$ (i.e. $\varepsilon_{v}^{s}=\varepsilon_{v}^{h}$ ), and becomes flat close to zero, as $\rho$ increases.

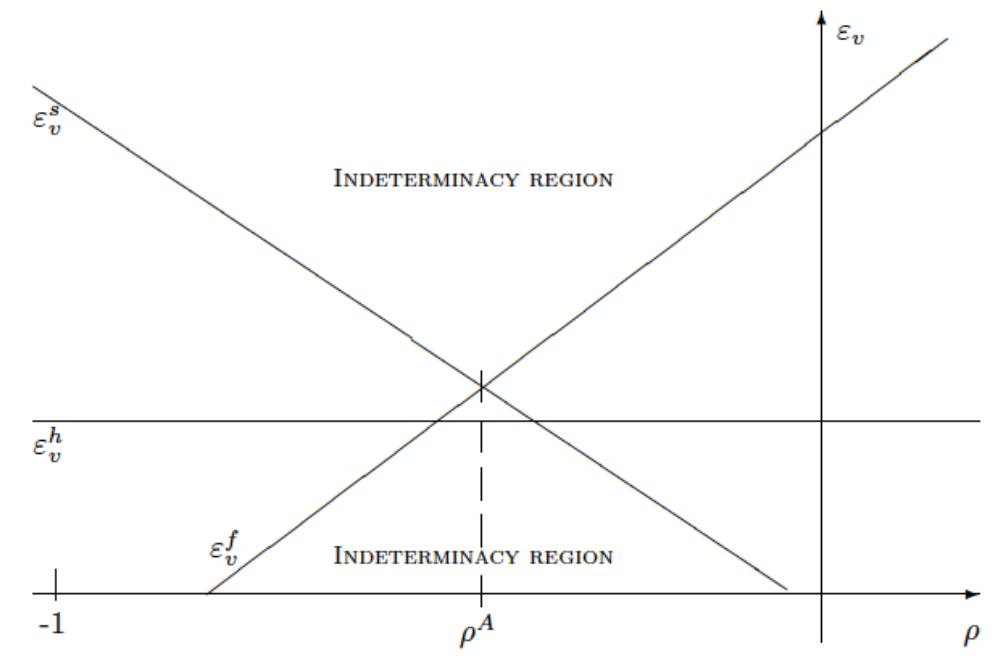

Figure 6: Stabilizing role of monetary policy with asset prices when $\eta_{1}>\gamma$ and $\varepsilon_{u} \geq \bar{\varepsilon}_{u}$.

To summarize, when $\eta_{1}<\gamma$, local indeterminacy occurs if $\varepsilon_{v}<\min \left(\varepsilon_{v}^{s}, \varepsilon_{v}^{f}, \varepsilon_{v}^{h}\right)$ and if $\varepsilon_{v}>\max \left(\varepsilon_{v}^{f}, \varepsilon_{v}^{s}\right)$ (see Figure 4). ${ }^{29}$ When $\eta_{1}>\gamma$ and $\varepsilon_{u}<\bar{\varepsilon}_{u}$, local indeterminacy emerges if $\varepsilon_{v}<\min \left(\varepsilon_{v}^{s}, \varepsilon_{v}^{f}\right)$ and if $\varepsilon_{v}>\max \left(\varepsilon_{v}^{s}, \varepsilon_{v}^{h}, \varepsilon_{v}^{f}\right)$ (see Figure 5). Finally, when $\eta_{1}>\gamma$ and $\varepsilon_{u} \geq \bar{\varepsilon}_{u}$, local indeterminacy arises if $\varepsilon_{v}<\min \left(\varepsilon_{v}^{s}, \varepsilon_{v}^{f}, \varepsilon_{v}^{h}\right)$ and if $\varepsilon_{v}>\max \left(\varepsilon_{v}^{f}, \varepsilon_{v}^{s}\right)$ (see Figure 6).

Now, we study how these critical bifurcation values, $\varepsilon_{v}^{s}, \varepsilon_{v}^{f}$ and $\varepsilon_{v}^{h}$, vary with respect to $\rho .^{30}$

Lemma 5 Under Assumptions 1-7, the effects of the monetary policy $\rho$ on the bifurcation values are given by the following derivatives:

$$
\text { 1. When } \eta_{1}<\gamma, \frac{d \varepsilon_{v}^{s}}{d \rho}>0, \quad \frac{d \varepsilon_{v}^{f}}{d \rho}<0 \quad \text { and } \quad \frac{d \varepsilon_{v}^{h}}{d \rho}=0 .
$$

\footnotetext{
${ }^{29}$ Figures 4-6 give just qualitative illustrations. Furthermore, Figure 4 depicts the stabilizing role of monetary policy when $\eta_{1}<\gamma$ and $\varepsilon_{u}>\varepsilon_{u}^{s}$ for $\rho=0$. If $\varepsilon_{u}<\varepsilon_{u}^{s}$ for $\rho=0$, then $\varepsilon_{v}^{s}$ would be positive in Figure 4.

${ }^{30}$ More details are available upon request.
} 
2. When $\eta_{1}>\gamma, \frac{d \varepsilon_{v}^{s}}{d \rho}<0, \quad \frac{d \varepsilon_{v}^{f}}{d \rho}>0 \quad$ and $\quad \frac{d \varepsilon_{v}^{h}}{d \rho}=0$.

Proof. See Appendix.

Let $\rho^{A}$ be the crossing point between $\varepsilon_{v}^{s}$ and $\varepsilon_{v}^{f} \cdot 31$ The next proposition summarizes the role of a monetary policy on local indeterminacy for a given value of $\alpha$ :

Proposition 8 Under Assumptions 1-8, the following generically holds:

1. If $-1<\rho<\rho^{A}$, the more passive the monetary policy is, the more stabilizing it is in the neighborhood of the steady state $b^{*}$.

2. If $\rho^{A}<\rho$, the more active the monetary policy is, the more stabilizing it is in the neighborhood of the steady state $b^{*}$.

Whatever the size of collateral effect and the degree of income effects, a sufficiently active monetary policy taking asset prices into account (i.e. $\rho>\rho^{A}$ ) hardens the condition on $\varepsilon_{v}$, which leads to local indeterminacy. Hence, an active monetary rule taking asset prices into account makes the economy more stable around the targeted steady state.

We remind that the multiplicity of steady states is connected to $\varepsilon_{v}<\varepsilon_{v}^{s}$. The next proposition summarizes, for a given value of $\alpha$, the role of a monetary policy on the multiplicity of steady states, which can be a source of global indeterminacy $^{32}$ :

Proposition 9 Under Assumptions 1-8, the following generically holds:

1. When $\eta_{1}<\gamma$, the more passive the monetary policy is, the smaller the range of values $\varepsilon_{v}$, under which the multiplicity of steady states exists, is.

2. When $\eta_{1}>\gamma$, the more active the monetary policy is, the smaller the range of values $\varepsilon_{v}$, under which the multiplicity of steady states exists, is.

We deduce from Proposition 9 that when $\eta_{1}<\gamma$, a passive monetary rule makes global indeterminacy less likely to emerge. This means that even if an active monetary rule can locally stabilize, a passive one may stabilize both locally and globally. In other words, the steady state $b^{*}$ is getting determinate, and the multiplicity of steady states disappears.

When $\eta_{1}>\gamma$, we have an opposite result: a sufficiently active monetary policy, taking asset prices into account, makes global indeterminacy less likely to emerge. The steady state $b^{*}$ becomes determinate, and the multiplicity of steady states disappears. Hence, when collateral sufficiently matters, an active monetary rule can stabilize both locally and globally.

\footnotetext{
${ }^{31}$ The value of $\rho^{A}$ is given in Appendix. We can easily show that when $\eta_{1}<\gamma, \rho^{A}>0$.

${ }^{32}$ From the steady state analysis (see Section 4.2 ), we know that $\varepsilon_{v}<\varepsilon_{v}^{s}$ is a sufficient condition to obtain the multiplicity of steady states. Therefore, ensuring $\varepsilon_{v}>\varepsilon_{v}^{s}$ is a way to eliminate, at least, stationary solutions not too far from $b^{*}=1$. This is what we call a globally stabilizing monetary policy.
} 
In any case, once asset prices are taken into account by the monetary authority, a monetary rule stabilizes for small income effects and rules out the multiplicity of steady states, which is not the case when the monetary rule responds to expected inflation only. More precisely, when collateral has a small effect on the credit share, a passive monetary rule is stabilizing, and when collateral sufficiently matters, an active one is stabilizing. Following the debate initiated by Bernanke and Gertler $(1999,2001)$ and recently advanced by several Governors of central bank or practitioners of monetary policy (Yellen (2009), Bernanke $(2010,2011))$, we provide a conclusion in favor of including asset prices in monetary policy rules. Although our theoretical framework differs from dynamic stochastic general equilibrium ones, our results are in accordance with some of other recent contributions: under credit market imperfections, a monetary policy should respond to movements in asset prices to rule out expectation-driven fluctuations.

\section{Concluding remarks}

We present a monetary overlapping generations model with two assets, bubble and money needed to transaction motives, and a collateral effect. The endogenous portfolio choice promotes expectation-driven fluctuations and the multiplicity of steady states for small income effects and arbitrarily small distortions.

When monetary policy only depends on expected inflation, a sufficiently active policy can stabilize expectation-driven fluctuations occurring for large income effects, if the collateral effect on the credit share is large enough. The role of collateral in our model may overturn the conclusions obtained by Sorger (2005). However, such a rule has no impact on the occurrence of expectationdriven fluctuations for small income effects and on the multiplicity of steady states.

In our model, a monetary policy including asset prices may rule out aggregate fluctuations. Indeed, a sufficiently active rule stabilizes fluctuations around the steady state both for small and large income effects, and whatever the collateral effect on the credit share. In addition, a monetary rule on asset prices can locally and globally stabilize fluctuations unlike a monetary rule which only responds to inflation. More precisely, when collateral has a small effect on the credit share, a passive monetary rule has a stabilizing role, and when collateral sufficiently matters, an active one has a stabilizing role. Our results mitigate the conclusions pronounced by Bernanke and Gertler (1999, 2001), and reinforced recently, for instance, by Carlstrom and Fuerst (2007). Focusing on consumers' credit constraints and endogenous bubble fluctuations, including asset prices in monetary policy rules is powerful to rule out macroeconomic instability.

Note that this previous analysis is also conducted for a given value of $\alpha$ (see Section 6.2). However, our results are not qualitatively modified by $\alpha$. Indeed, for a sufficiently large collateral effect on the credit share (i.e. $\gamma<\eta_{1}$ ), an increase in $\alpha$ reinforces mechanisms which lead to stabilize both locally and 
globally, taking into account that $\rho$ is not too small. ${ }^{33}$ Nonetheless, for a small collateral effect (i.e. $\gamma>\eta_{1}$ ), an increase in $\alpha$ reinforces mechanisms which locally destabilize for large values of $\varepsilon_{v}$ or a sufficiently large value of $\rho$.

Finally, our qualitative results are obtained for all value of monetary growth factor's target $\mu^{*}$. Therefore, these conclusions are compatible with a target $\mu^{*}$ which maximizes households' welfare at the steady state. When the monetary rule including asset prices is not too passive, $\mu^{*}=1$ is an optimal rule. We recognize the Friedman rule: no money growth and a nominal interest rate equals to zero $\left(\mu^{*}=1+i=1\right)$. The intertemporal choices of households are no longer affected by the distortions due to money holdings. From Eq. (30) at the normalized steady state, we obtain $u^{\prime}(e-1 /[1-\gamma(1)])=\beta^{*} v^{\prime}(1 /[1-\gamma(1)])$, which corresponds to the Phelps Golden rule in a monetary OLG model without population growth. Thus, a stabilizing monetary rule, which eliminates the cost of fluctuations, may be in accordance with welfare maximisation at the steady state.

${ }^{33}$ This could be shown using the bifurcation values $\varepsilon_{v}^{f}, \varepsilon_{v}^{h}$ and $\varepsilon_{v}^{s}$ (see Appendix). 


\section{Appendix}

\section{Proof of Lemma 1}

We maximize the Lagrangian function:

$$
\begin{aligned}
& u\left(c_{t}\right)+\beta v\left(d_{t+1}\right) \\
& +\lambda_{1 t}\left(e+\tau_{t}-\pi_{t+1} m_{t+1}-b_{t}-c_{t}\right) \\
& +\lambda_{2 t}\left(m_{t+1}+\frac{1+i_{t+1}}{\pi_{t+1}} b_{t}-d_{t+1}\right) \\
& +\lambda_{3 t}\left(m_{t+1}-\gamma\left(b_{t}\right) d_{t+1}\right)
\end{aligned}
$$

with respect to $\left(c_{t}, d_{t+1}, m_{t+1}, b_{t}, \lambda_{1 t}, \lambda_{2 t}, \lambda_{3 t}\right)$. Since $\lambda_{1 t}=u^{\prime}\left(c_{t}\right)>0$, then Eq. (8) becomes binding. Because

$$
\begin{aligned}
& \lambda_{2 t}=\lambda_{1 t} \frac{1+\gamma^{\prime}\left(b_{t}\right) d_{t+1} \pi_{t+1}}{\frac{1+i_{t+1}}{\pi_{t+1}}+\gamma^{\prime}\left(b_{t}\right) d_{t+1}} \\
& \lambda_{3 t}=\lambda_{1 t}\left(\pi_{t+1}-\frac{1+\pi_{t+1} \gamma^{\prime}\left(b_{t}\right) d_{t+1}}{\frac{1+i_{t+1}}{\pi_{t+1}}+\gamma^{\prime}\left(b_{t}\right) d_{t+1}}\right)
\end{aligned}
$$

strict positivity of $\lambda_{2 t}$ and $\lambda_{3 t}$ requires

$$
\pi_{t+1}>\frac{1+\gamma^{\prime}\left(b_{t}\right) \pi_{t+1} d_{t+1}}{\frac{1+i_{t+1}}{\pi_{t+1}}+\gamma^{\prime}\left(b_{t}\right) d_{t+1}}>0
$$

The inequality $1+\gamma^{\prime}\left(b_{t}\right) \pi_{t+1} d_{t+1}>0$ is equivalent to the inequality (11). Moreover, $i_{t+1}>0$ implies $\left(1+i_{t+1}\right)+\gamma^{\prime}\left(b_{t}\right) \pi_{t+1} d_{t+1}>1+\gamma^{\prime}\left(b_{t}\right) \pi_{t+1} d_{t+1}$, which ensures that the inequality (48) holds.

\section{Proof of Lemma 2}

We compute the Hessian matrix of the Lagrangian function (45) with respect to $\left(c_{t}, d_{t+1}, m_{t+1}, b_{t}, \lambda_{1 t}, \lambda_{2 t}, \lambda_{3 t}\right)^{34}$ :

$$
H \equiv\left[\begin{array}{ccccccc}
u^{\prime \prime} & 0 & 0 & 0 & -1 & 0 & 0 \\
0 & \beta v^{\prime \prime} & 0 & -\lambda_{3} \gamma^{\prime} & 0 & -1 & -\gamma \\
0 & 0 & 0 & 0 & -\pi & 1 & 1 \\
0 & -\gamma^{\prime} \lambda_{3} & 0 & -\gamma^{\prime \prime} \lambda_{3} d & -1 & \frac{1+i}{\pi} & -\gamma^{\prime} d \\
-1 & 0 & -\pi & -1 & 0 & 0 & 0 \\
0 & -1 & 1 & \frac{1+i}{\pi} & 0 & 0 & 0 \\
0 & -\gamma & 1 & -\gamma^{\prime} d & 0 & 0 & 0
\end{array}\right]
$$

In order to get a strict local maximum, we need to check the negative definition of $H$ over the set of points satisfying the constraints. Let $p$ and $n$ the numbers of constraints and variables. If the determinant of $H$ has sign $(-1)^{n}$,

${ }^{34}$ For simplicity, the arguments of the functions and the time subscripts are omitted. 
and the last $n-p$ diagonal principal minors have alternating signs, then the optimum is a regular local maximum. In our case $n=4$ and $p=3$. Therefore, we simply require $\operatorname{det} H>0$, that is,

$$
\begin{aligned}
\operatorname{det} H= & -u^{\prime \prime}\left[\pi\left(\gamma^{\prime} d+\frac{1+i}{\pi} \gamma\right)+(1-\gamma)\right]^{2} \\
& -\beta v^{\prime \prime}\left(\gamma^{\prime} d+\frac{1+i}{\pi}\right)^{2} \\
& +\lambda_{3}(1-\gamma)\left[2\left(\gamma^{\prime 2} d+\gamma^{\prime} \frac{1+i}{\pi}\right)+\gamma^{\prime \prime} d(1-\gamma)\right]>0
\end{aligned}
$$

Using Eqs. (9) and (10), we find $d_{t+1}=\frac{b_{t}}{1-\gamma\left(b_{t}\right)} \frac{1+i_{t+1}}{\pi_{t+1}}$. Substituting in Eq. (50), we get:

$$
\operatorname{det} H=-\left(\frac{1+i}{\pi}\right)^{2}\left[\chi_{0}+\chi_{1}^{2} u^{\prime \prime}+\beta v^{\prime \prime}\left(1-\eta_{1}\right)^{2}\right]>0
$$

where

$$
\begin{aligned}
\chi_{0} & \equiv \lambda_{3} \eta_{1} \frac{(1-\gamma)^{2}}{b}\left[2\left(1-\eta_{1}\right)-\eta_{2}\right] \frac{\pi}{1+i} \\
\chi_{1} & \equiv \pi\left(\gamma-\eta_{1}\right)+\frac{1-\gamma}{1+i} \pi
\end{aligned}
$$

$\chi_{0}+\chi_{1}^{2} u^{\prime \prime}<0$ is a sufficient condition for $\operatorname{det} H>0$. Hence, the second order conditions are satisfied if ${ }^{35}$ :

$$
\varepsilon_{u}>\frac{c(1-\gamma)^{2} / b}{\left[1-\gamma+(1+i)\left(\gamma-\eta_{1}\right)\right]^{2}} i \eta_{1}\left(2-\frac{\eta_{2}}{1-\eta_{1}}\right) \equiv \tilde{\varepsilon}_{u}
$$

whatever the value of $\varepsilon_{v} \geq 0$

\section{Proof of Proposition 1}

A steady state $b$ is a solution of $g(b)=h(b)$, with:

$$
\begin{aligned}
g(b) & \equiv \frac{u^{\prime}\left(e-\frac{b}{1-\gamma(b)}\right)}{\beta v^{\prime}\left(\frac{b}{1-\gamma(b)}\right)} \\
h(b) & \equiv \frac{1-\eta_{1}(b)}{1-\gamma(b)+\left[\gamma(b)-\eta_{1}(b)\right] \mu(b)}
\end{aligned}
$$

Since $\frac{b}{1-\gamma(b)}$ is increasing in $b$ and $c>0$, then $b<\bar{b}$, where $\bar{b}>0$ is such that $e=\frac{\bar{b}}{1-\gamma(\bar{b})} .{ }^{36}$ Therefore, all the stationary solutions $b$ belong to $(0, \bar{b})$.

\footnotetext{
${ }^{35}$ For simplicity, the arguments of the functions and the time subscripts are omitted.

${ }^{36}$ With our specification for $\gamma(b)$ function, $\bar{b}$ is well defined under Assumption 3.
} 
To prove the existence of a stationary solution $b$, we use the continuity of $g(b)$ and $h(b)$. From Eqs. (32), (53) and (54), we determine the boundary values of $g(b)$ and $h(b)$ :

$$
\begin{gathered}
\lim _{b \rightarrow 0} g(b)=\frac{u^{\prime}(e)}{\beta v^{\prime}(0)}=0^{+}, \lim _{b \rightarrow \bar{b}} g(b)=+\infty \\
\lim _{b \rightarrow 0} h(b)=\frac{1-\eta_{1}(0)}{1-\gamma(0)+\left[\gamma(0)-\eta_{1}(0)\right] \mu(0)} \geq 0 \\
\lim _{b \rightarrow \bar{b}} h(b)=\frac{1-\eta_{1}(\bar{b})}{1-\gamma(\bar{b})+\left[\gamma(\bar{b})-\eta_{1}(\bar{b})\right] \mu(\bar{b})}>0
\end{gathered}
$$

We have $\lim _{b \rightarrow \bar{b}} g(b)>\lim _{b \rightarrow \bar{b}} h(b)$. If $-1<\rho \leq 0, \mu(0)<+\infty$, which implies $\lim _{b \rightarrow 0} g(b)<\lim _{b \rightarrow 0} h(b)$. However, if $\rho>0, \mu(0)=+\infty$, which implies $g(0)=h(0)$. In this case, the existence of a steady state $b \in(0, \bar{b})$, solving $g(b)=h(b)$, is ensured by $\varepsilon_{g}(0)<\varepsilon_{h}(0)$, where:

$$
\begin{aligned}
\varepsilon_{g}(b) \equiv \frac{g^{\prime}(b) b}{g(b)}= & \varepsilon_{u}(c) \frac{1-\eta_{1}(b)}{1-\gamma(b)} \frac{b}{c}+\left[1-\eta_{1}(b)\right] \varepsilon_{v}(d)>0 \\
\varepsilon_{h}(b) \equiv \frac{h^{\prime}(b) b}{h(b)}= & \eta_{1}(b) \frac{[1-\gamma(b)][\mu(b)-1]\left\{2\left[1-\eta_{1}(b)\right]-\eta_{2}(b)\right\}}{\left[1-\eta_{1}(b)\right]\left\{1-\gamma(b)+\mu(b)\left[\gamma(b)-\eta_{1}(b)\right]\right\}} \\
& +\frac{\rho}{1+\alpha} \frac{\mu(b)\left[\gamma(b)-\eta_{1}(b)\right]}{1-\gamma(b)+\mu(b)\left[\gamma(b)-\eta_{1}(b)\right]}
\end{aligned}
$$

Under Assumption 4, this last condition is satisfied. A sufficient condition for uniqueness is $\varepsilon_{h}(b)<\varepsilon_{g}(b)$ for all $b \in(0, \bar{b})$, or equivalently,

$$
\begin{gathered}
\varepsilon_{u}(c) \frac{b}{c(1-\gamma(b))}+\varepsilon_{v}(d)>\frac{\eta_{1}(b)}{1-\eta_{1}(b)} \frac{[1-\gamma(b)][\mu(b)-1]}{1-\gamma(b)+\mu(b)\left[\gamma(b)-\eta_{1}(b)\right]} \\
\left(2-\frac{\eta_{2}(b)}{1-\eta_{1}(b)}\right)+\frac{\rho}{1+\alpha} \frac{\mu(b)\left[\gamma(b)-\eta_{1}(b)\right]}{1-\gamma(b)+\mu(b)\left[\gamma(b)-\eta_{1}(b)\right]} \frac{1}{1-\eta_{1}(b)}
\end{gathered}
$$

\section{Proof of Proposition 3}

Using the notations of the proof of Proposition 1, we know that $g(\bar{b})>h(\bar{b})$ and under Assumption 4, $g(b)<h(b)$ for $b>0$ but arbitrarily close to 0 . Since $b^{*}=1$ is a steady state, we have: $g(1)=h(1)$. If the inequality (33) is satisfied, we have $g^{\prime}(1)<h^{\prime}(1)$, then by continuity there exist at least two other steady states, $b_{1}$ and $b_{2}$ such that $b_{1}<1<b_{2}$. The number of steady states is generically odd. 


\section{Proof of Lemma 3}

Substituting Eq. (28) into Eq. (26) and differentiating around the NSS with respect to $b_{t-1}, b_{t}$ and $b_{t+1}$, we obtain the following linearization ${ }^{37}$ :

$$
\begin{aligned}
& {\left[\varepsilon_{v}-\frac{1-\gamma+\mu^{*}\left(\gamma-\eta_{1}\right) \frac{1}{1+\alpha}}{1-\gamma+\mu^{*}\left(\gamma-\eta_{1}\right)}\right] d b_{t+1}+\left[\frac{1}{(1-\gamma)} \frac{\varepsilon_{u}}{c^{*}}-\eta_{1} \varepsilon_{v}+1\right.} \\
& \left.-\frac{(1-\gamma)\left(\mu^{*}-1\right) \eta_{1}}{1-\gamma+\mu^{*}\left(\gamma-\eta_{1}\right)}\left(2-\frac{\eta_{2}}{1-\eta_{1}}\right)+\frac{\mu^{*}\left(\gamma-\eta_{1}\right)}{1-\gamma+\mu^{*}\left(\gamma-\eta_{1}\right)} \frac{-\alpha-\rho+\eta_{1} / \gamma}{1+\alpha}\right] d b_{t} \\
& -\left[\frac{\eta_{1}}{1-\gamma} \frac{\varepsilon_{u}}{c^{*}}+\frac{\mu^{*}\left(\gamma-\eta_{1}\right)}{1-\gamma+\mu^{*}\left(\gamma-\eta_{1}\right)} \frac{\eta_{1} / \gamma}{1+\alpha}\right] d b_{t-1}=0
\end{aligned}
$$

Lemma 3 follows.

\section{Bifurcation values of $\varepsilon_{v}$}

$\varepsilon_{v}^{s}$ is defined by $1-T\left(\varepsilon_{v}\right)+D\left(\varepsilon_{v}\right)=0$ :

$$
\varepsilon_{v}^{s}=\frac{1}{c^{*}(1-\gamma)}\left(\varepsilon_{u}^{s}-\varepsilon_{u}\right),
$$

where $\varepsilon_{u}^{s}$ is given by Eq. (42).

$\varepsilon_{v}^{f}$ is defined by $1+T\left(\varepsilon_{v}\right)+D\left(\varepsilon_{v}\right)=0$ :

$$
\begin{aligned}
\varepsilon_{v}^{f}=\frac{\varepsilon_{u}}{c^{*}(1-\gamma)}+\frac{1-\gamma}{1-\gamma+\mu^{*}\left(\gamma-\eta_{1}\right)} & {\left[\frac{2}{1+\eta_{1}}-\frac{\eta_{1}}{1+\eta_{1}}\left(\mu^{*}-1\right)\left(2-\frac{\eta_{2}}{1-\eta_{1}}\right)\right] } \\
+ & \frac{2}{1+\eta_{1}} \frac{\mu^{*}\left(\gamma-\eta_{1}\right)}{1-\gamma+\mu^{*}\left(\gamma-\eta_{1}\right)} \frac{1+\eta_{1} / \gamma-\rho / 2}{1+\alpha}
\end{aligned}
$$

$\varepsilon_{v}^{h}$ is defined by $D=1$ :

$\varepsilon_{v}^{h}=\frac{1-\gamma}{1-\gamma+\mu^{*}\left(\gamma-\eta_{1}\right)}+\frac{\mu^{*}\left(\gamma-\eta_{1}\right)^{2}}{1-\gamma+\mu^{*}\left(\gamma-\eta_{1}\right)} \frac{1 / \gamma}{1+\alpha}-\eta_{1} \frac{\varepsilon_{u}}{c^{*}(1-\gamma)}$

\section{Critical values of $\alpha$}

$\alpha^{A}$ is defined by $\bar{\varepsilon}_{v}=0$ :

$$
\alpha^{A} \equiv-\frac{1-\gamma+\mu^{*}\left(\gamma-\eta_{1}\right)}{1-\gamma}
$$

$\alpha^{B}$ is defined by $\varepsilon_{v}^{f}=\varepsilon_{v}^{h}$ :

$$
\alpha^{B} \equiv-\frac{\frac{\mu^{*}\left(\gamma-\eta_{1}\right)}{1-\gamma+\mu^{*}\left(\gamma-\eta_{1}\right)}\left[1-\eta_{1}+\left(3+\eta_{1}\right) \eta_{1} / \gamma\right]}{\frac{\varepsilon_{u}}{c^{*}} \frac{\left(1+\eta_{1}\right)^{2}}{1-\gamma}+\frac{1-\gamma}{1-\gamma+\mu^{*}\left(\gamma-\eta_{1}\right)}\left[1-\eta_{1}-\eta_{1}\left(\mu^{*}-1\right)\left(2-\frac{\eta_{2}}{1-\eta_{1}}\right)\right]}-1
$$

\footnotetext{
${ }^{37}$ The arguments of the functions are omitted.
} 
Proof of Lemma $4(\rho=0)$

$$
\begin{aligned}
\frac{d \varepsilon_{v}^{s}}{d \alpha} & =-\frac{1}{(1+\alpha)^{2}} \frac{\mu^{*}\left(\gamma-\eta_{1}\right)}{1-\gamma+\mu^{*}\left(\gamma-\eta_{1}\right)} \frac{\rho}{1-\eta_{1}}=0 \\
\frac{d \varepsilon_{v}^{f}}{d \alpha} & =-\frac{1}{(1+\alpha)^{2}} \frac{2}{1+\eta_{1}} \frac{\mu^{*}\left(\gamma-\eta_{1}\right)}{1-\gamma+\mu^{*}\left(\gamma-\eta_{1}\right)}\left(1+\eta_{1} / \gamma-\rho / 2\right)
\end{aligned}
$$

Lemma 4 follows.

Proof of Lemma 5

$$
\begin{aligned}
\frac{d \varepsilon_{v}^{s}}{d \rho} & =\frac{1}{1+\alpha} \frac{\mu^{*}\left(\gamma-\eta_{1}\right)}{1-\gamma+\mu^{*}\left(\gamma-\eta_{1}\right)} \frac{1}{1-\eta_{1}} \\
\frac{d \varepsilon_{v}^{f}}{d \rho} & =-\frac{1}{1+\alpha} \frac{1}{1+\eta_{1}} \frac{\mu^{*}\left(\gamma-\eta_{1}\right)}{1-\gamma+\mu^{*}\left(\gamma-\eta_{1}\right)} \\
\frac{d \varepsilon_{v}^{h}}{d \rho} & =0
\end{aligned}
$$

Lemma 5 follows.

\section{Critical value of $\rho$}

$\rho^{A}$ is defined by $\varepsilon_{v}^{f}=\varepsilon_{v}^{s}$ :

$$
\begin{aligned}
\rho^{A} \equiv & (1+\alpha)\left\{\frac{\varepsilon_{u}}{c^{*}(1-\gamma)} \frac{1-\gamma+\mu^{*}\left(\gamma-\eta_{1}\right)}{\mu^{*}\left(\gamma-\eta_{1}\right)}\left(1-\eta_{1}^{2}\right)\right. \\
& +\frac{1-\gamma}{\mu^{*}\left(\gamma-\eta_{1}\right)}\left[1-\eta_{1}-\eta_{1}\left(\mu^{*}-1\right)\left(2-\frac{\eta_{2}}{1-\eta_{1}}\right)\right] \\
& \left.+\frac{\left(1-\eta_{1}\right)\left(1+\eta_{1} / \gamma\right)}{1+\alpha}\right\}
\end{aligned}
$$

\section{References}

[1] Benhabib, J., S. Schmitt-Grohé and M. Uribe (2001), "The perils of Taylor rules", Journal of Economic Theory 96, 40-69.

[2] Bernanke, B. (2010), "Monetary Policy and the Housing Bubble by Ben S. Bernanke Chairman" At the Annual Meeting of the American Economic Association, Atlanta, Georgia, January 3. 
[3] Bernanke, B. (2011), "Remarks by Chairman Ben S. Bernanke" At the 56th Economic Conference Federal Reserve Bank of Boston, Boston, Massachusetts, October 18.

[4] Bernanke, B. and M. Gertler (1999), "Monetary policy and asset price volatility", Federal Reserve Bank of Kansas City Economic Review 84, $17-52$.

[5] Bernanke, B. and M. Gertler M. (2001), "Should central banks respond to movements in asset prices?", American Economic Review 91, 253-257.

[6] Bosi, S. and T. Seegmuller (2010), "On rational exuberance", Mathematical Social Sciences 59, 249-270.

[7] Campbell, J. (2003), "Consumption-based asset pricing", In: G. Constantinides, M. Harris, R. Stulz (Eds.), Handbook of the Economics of Finance (Amsterdam: North-Holland) 1B, 803-887.

[8] Campbell, J. and G. Mankiw (1989), "Consumption, income and interest rates: reinterpreting the time series evidence", In: O. Blanchard and S. Fisher (Eds.) NBER Macroeconomics Annual (Cambridge MA: MIT Press), 185-216.

[9] Carlstrom, C. T. and T. S. Fuerst (2007), "Asset prices, nominal rigidities, and monetary policy", Review of Economics Dynamics 10, 256-275.

[10] Cazzavillan, G., T. Lloyd-Braga and P. Pintus (1998), "Multiple steady states and endogenous fluctuations with increasing returns to scale in production ", Journal of Economic Theory 80, 60-107.

[11] Crettez, B., P. Michel and B. Wigniolle (1999), "Cash-in-advance constraints in the Diamond overlapping generations model: neutrality and optimality of monetary policy", Oxford Economic Papers 51, 431-452.

[12] Fahri, E. and J. Tirole (2011), "Bubbly liquidity", Review of Economic Studies, forthcoming.

[13] Gaballo, G. (2012) "Rational Inattention to News: The Perils of Forward Guidance", Working Paper N 416, Banque de France.

[14] Gali, J. (2011), "Monetary policy and rational asset price bubbles", miméo, CREI.

[15] Gilchrist, S. and J. V. Leahy (2002), "Monetary policy and asset prices", Journal of Monetary Economics 49, 75-97.

[16] Grandmont, J.-M. (1985), "On endogenous competitive business cycles", Econometrica 53, 995-1045.

[17] Grandmont, J.-M. (1986), "Stabilizing competitive business cycles", Journal of Economic Theory 40, 57-76. 
[18] Grandmont, J.-M., P. Pintus and R. de Vilder (1998), "Capital-labour substitution and competitive nonlinear endogenous business cycles", Journal of Economic Theory 80, 14-59.

[19] Greenspan, A. (1996), "Remarks by Chairman Alan Greenspan" At the Annual Dinner and Francis Boyer Lecture of The American Enterprise Institute for Public Policy Research, Washington D.C., December 5.

[20] Hahn, F. and R. Solow (1995), A Critical Essay on Modern Macroeconomic Theory, Basil Blackwell, Oxford.

[21] Hellwig, C. and G. Lorenzoni (2009), "Bubbles and self-enforcing debt", Econometrica 77, 1137-1164.

[22] Kamihigashi, T (2008), "The spirit of capitalism, stock market bubbles and output fluctuations ", International Journal of Economic Theory 4, 3-28

[23] Kocherlakota, N. R. (1992), "Bubbles and constraints on debt accumulation", Journal of Economic Theory 57, 245-256.

[24] Kocherlakota, N. R. (2009), "Bursting bubbles: consequences and cures", Federal Reserve Bank of Minneapolis.

[25] LeRoy, S. and R. Porter (1981), "The present value relation: tests based on variance bounds", Econometrica 49, 555-584.

[26] Lucas Jr., R.E. and N. Stokey (1987). "Money and interest in a cash-inadvance economy", Econometrica 55, 491-513.

[27] Michel, P. and B. Wigniolle (2003), "Temporary bubbles", Journal of Economic Theory 112, 173-183.

[28] Michel, P. and B. Wigniolle (2005), "Cash-in-advance constraints, bubbles and monetary policy", Macroeconomic Dynamics 9, 28-56.

[29] Nutahara, K. (2010), "Asset prices and monetary policy in a sticky-price economy with financial frictions ", RIETI Discussion Paper Series 10-E-060.

[30] Samuelson, P.A. (1958), "An exact consumption-loan model of interest with or without the social contrivance of money", Journal of Political Economy 66, 467-482.

[31] Shiller, R. J. (1981), "Do stock prices move too much to be justified by subsequent changes in dividends?", American Economic Review 71, 421436.

[32] Shiller, R. J. (1989), Market Volatility, MIT Press, Cambridge, MA.

[33] Shiller, R. J. (2000), Irrational Exuberance, Princeton University Press, Princeton. 
[34] Singh, A. and S. Stone (2010), "Asset prices, monetary policy and determinacy", 6th Annual Conference on Economic Growth and Development, New Delhi, India, December 16-18.

[35] Sorger, G. (2005), "Active and passive monetary policy in an overlapping generations model", Review of Economic Dynamics 8, 731-748.

[36] Tirole, J. (1982), "On the possibility of speculation under rational expectations", Econometrica 50, 1163-1181.

[37] Tirole, J. (1985), "Asset bubbles and overlapping generations", Econometrica 53, 1071-1100.

[38] Weil, P. (1987), "Confidence and the real value of money in overlapping generations models", Quarterly Journal of Economics 102, 1-22.

[39] Wigniolle, B. (2012), "Optimism, pessimism and financial bubbles ", CES Working Paper 2012.05, University Paris 1.

[40] Yellen, A. (2009), "A Minsky Meltdown: Lessons for Central Bankers" Presentation to the 18th Annual Hyman P. Minsky Conference on the State of the U.S. and World Economies, New York City, April 16. 